\title{
REVIEWS
}

Check for updates

\section{Constitutive immune mechanisms: mediators of host defence and immune regulation}

Søren R. Paludan $\mathbb{1}^{1,2 凶}{ }^{\text {, Thomas Pradeu }}{ }^{3,4}$, Seth L. Masters $\mathbb{B}^{5,6}$ and Trine H. Mogensen ${ }^{1,7,8}$

Abstract | The immune system enables organisms to combat infections and to eliminate endogenous challenges. Immune responses can be evoked through diverse inducible pathways. However, various constitutive mechanisms are also required for immunocompetence. The inducible responses of pattern recognition receptors of the innate immune system and antigen-specific receptors of the adaptive immune system are highly effective, but they also have the potential to cause extensive immunopathology and tissue damage, as seen in many infectious and autoinflammatory diseases. By contrast, constitutive innate immune mechanisms, including restriction factors, basal autophagy and proteasomal degradation, tend to limit immune responses, with loss-of-function mutations in these pathways leading to inflammation. Although they function through a broad and heterogeneous set of mechanisms, the constitutive immune responses all function as early barriers to infection and aim to minimize any disruption of homeostasis. Supported by recent human and mouse data, in this Review we compare and contrast the inducible and constitutive mechanisms of immunosurveillance.

${ }^{1}$ Department of Biomedicine, Aarhus University, Aarhus, Denmark.

${ }^{2}$ Sahlgrenska Academy, University of Gothenburg, Gothenburg, Sweden.

${ }^{3}$ CNRS UMR 5164 ImmunoConcept, University of Bordeaux, Bordeaux, France.

${ }^{4}$ Department of Biological and Medical Sciences, University of Bordeaux Bordeaux, France.

${ }^{5}$ Inflammation Division, The Walter and Eliza Hall Institute, Melbourne, VIC, Australia.

\section{${ }^{6}$ Department of Medical} Biology, The University of Melbourne, Melbourne, VIC, Australia.

${ }^{7}$ Department of Clinical Medicine, Aarhus University, Aarhus, Denmark.

${ }^{8}$ Department of Infectious Diseases, Aarhus University Hospital, Aarhus, Denmark.

凶e-mail: srp@biomed.au.dk https://doi.org/10.1038/ s41577-020-0391-5
A major challenge for living organisms is to maintain homeostasis in response to changes in external and internal environments. These include alterations in nutrient and water supplies, physical stress, temperature changes, physiological stress, infections and malignancies ${ }^{1}$. Through billions of years of evolution, the forms of life and biological processes that cope with these challenges in the most successful way have been selected. One challenge that all organisms have to deal with is the elimination of microorganisms and of abnormal or damaged cellular material. The ideal immune response would eliminate the potential threat and re-establish homeostasis without causing excessive damage to healthy cells and tissues. However, immune responses to infections are often disruptive and can cause marked tissue damage $^{2,3}$. Such responses are evolutionarily advantageous when the benefit of eliminating the challenge outweighs the risk of associated tissue damage and the requirement for regeneration. However, for potential challenges that occur frequently but rarely develop into serious homeostasis-altering threats, it is not desirable to mount systemic or potentially disruptive immune responses. In addition, vigorous immune responses are not desirable in organs and tissues that are particularly sensitive to immune-mediated damage, such as the brain. Therefore, the ideal immune response has checks and balances, which allow the organism to modulate the magnitude and duration of the response according to the nature of the threat caused by the challenge.

The mammalian immune system, as we understand it today, is induced mainly by two types of receptor systems, the germline-encoded pattern recognition receptors (PRRs), which initiate innate immune responses, and the antigen-specific receptors generated through gene rearrangement after antigen encounter, which initiate adaptive immune responses ${ }^{4-6}$. The immune responses induced by PRRs, such as Toll-like receptors (TLRs), interact with those induced by antigen-specific receptors; this interaction is notably represented by dendritic cells, which rely on PRR-driven cues to initiate dendritic cell maturation for the stimulation of lymphocytes through antigen-specific receptors ${ }^{5}$. However, the research literature contains numerous reports of host defence activities that occur independently of both PRR-based immunity and antigen-specific receptors ${ }^{7-10}$, and emerging evidence suggests that several of these mechanisms have non-redundant roles in host defence in humans ${ }^{11,12}$. Here we review the literature on this topic by focusing on constitutive immune mechanisms. On the basis of this analysis, and by integrating concepts previously reviewed ${ }^{13}$, we propose that this constitutive layer of innate immunity exerts early host defence activities through specific molecular mechanisms and at the same time limits PRR activation as a specific feature. 


\section{Pattern recognition}

receptors

(PRRs). A family of germlineencoded immune receptors, including the Toll-like receptors, that detect immunostimulatory molecules to activate signal transduction and gene expression, which induces antimicrobial and inflammatory responses.

Constitutive immune mechanisms

Host mechanisms that are constitutively present in an active or latent form and thus can exert host defence activities immediately, independently of inducible processes.

\section{Constitutive and inducible mechanisms}

The innate immune system uses both constitutive and inducible mechanisms to eliminate infections and damaged self to maintain homeostasis (FIG. 1). Although the constitutive mechanisms have the advantage of providing an immediate response to a danger signal, they lack the potential to amplify the response. In addition, constitutive mechanisms consume energy to remain operative, and there are hence limits to how many of these can be maintained in any one organism. By contrast, inducible mechanisms such as those mediated through PRRs, as well as antigen-specific receptors, are activated only in response to stimuli and have the ability to amplify signals many times. Hence, inducible mechanisms can give rise to very strong and efficient immune responses, but can also lead to excess inflammation and immunopathology. Given their amplification potential, inducible immune mechanisms require tight control and negative regulatory systems.

The constitutive immune mechanisms can be divided into the chemical and physical barriers of the body, such as skin, saliva, stomach acid and urine flow, which are not the focus of this Review, and various molecularly

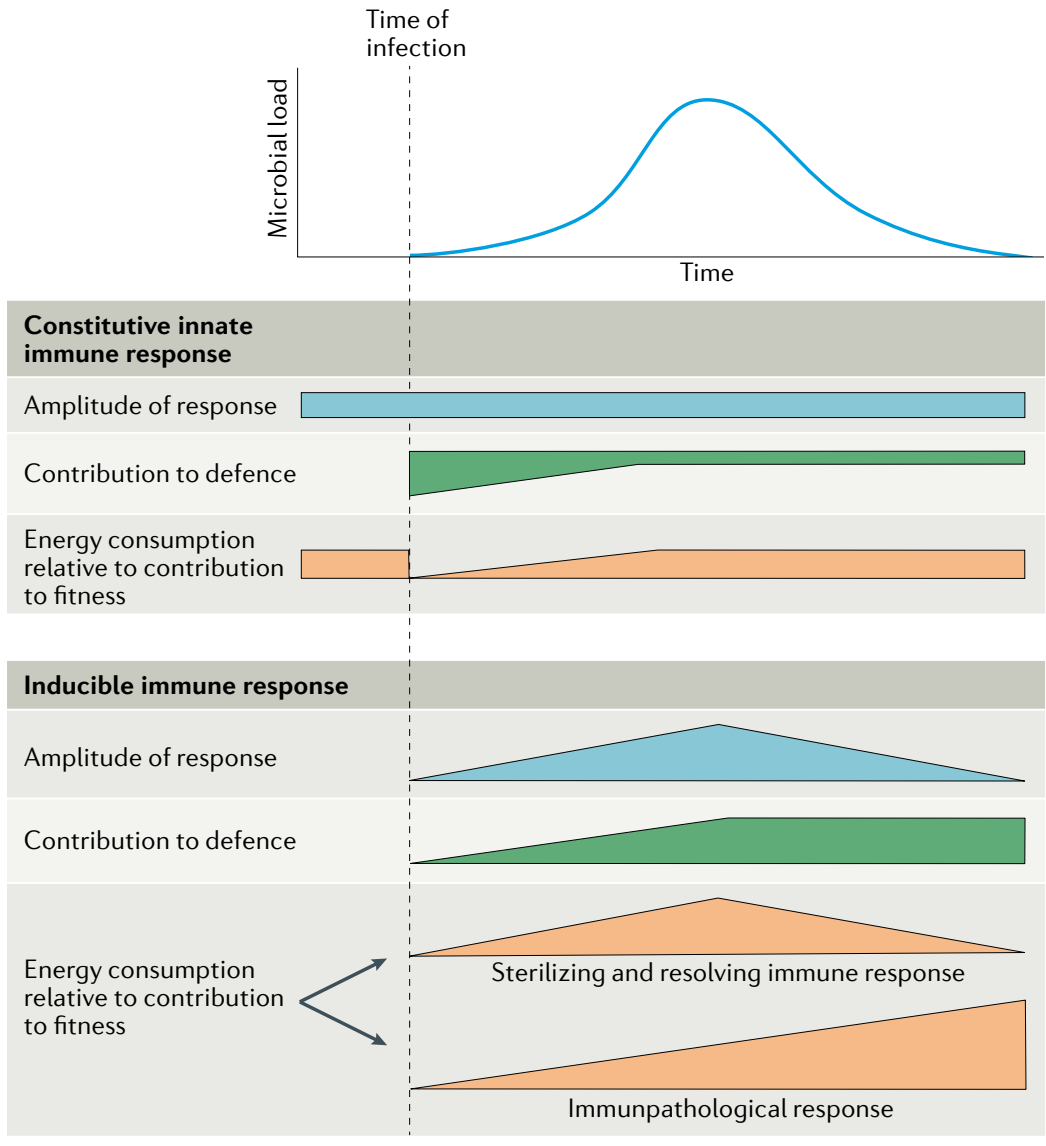

Fig. 1 Constitutive innate immune responses versus inducible immune responses. Illustration of how constitutive and inducible immune responses vary over time during the course of a generalized infection, and their impact on host defence, energy consumption and host fitness. In the case of a sterilizing and resolving immune response, the additional energy consumption required by the inducible immune response is balanced by the re-establishment of homeostasis. By contrast, in the case of an immunopathological response, the energy that is consumed to mount an inducible response does not benefit the host and instead leads to tissue damage and disruption of homeostasis. defined mechanisms that control microbial infection and/or replication ${ }^{1}$. Although these mechanisms have been known for many years, they have generally been considered to have only minor roles in the immune system, and evidence has been lacking as to their specific, non-redundant functions in host defence. Consequently, they have not received much attention in front-line immunology research. Here we discuss the constitutive innate immune responses in comparison with the better-described inducible innate responses triggered by PRRs. In addition, we present evidence suggesting that efficient action of constitutive innate immune mechanisms leads to both antimicrobial activity and mitigation of PRR-driven activities (FIG. 2).

PRR-activated inducible innate immune responses. PRRs detect pathogen-associated molecular patterns (PAMPs), microorganism-associated molecular patterns ${ }^{14}$, hostderived danger-associated molecular patterns ${ }^{15}$ and molecular signatures associated with homeostasisaltering molecular processes ${ }^{16}$. These molecular patterns activate PRR signalling, which ultimately leads to the transcription of antimicrobial and proinflammatory genes. Downstream activities of PRR signalling include the production of type I interferon (interferon- $\alpha$ (IFN $\alpha$ ) and IFN $\beta$ ), IL- $1 \beta$ and tumour necrosis factor (TNF). These cytokines, in turn, activate antimicrobial and proinflammatory activities, as well as the maturation of antigen-specific adaptive immune responses ${ }^{17,18}$. PRR-based immune responses can be highly potent, and numerous inflammatory diseases are driven by excessive PRR signalling pathways ${ }^{2,19,20}$ (BOX 1). However, the nature of PRR-based immunity is influenced by many factors, and it is worth mentioning that the gut microbiota and chronic viral infections can induce PRR-based, host-beneficial responses that tend towards tolerance rather than inflammation ${ }^{21,22}$. Nevertheless, given the potency of PRR-based immunity, full activation of PRR-driven immune responses each time a microorganism is encountered may not be beneficial for an organism in the longer term. Moreover, it is essential to control the activation and duration of PRR signalling-induced activities. This is achieved through multiple mechanisms, including two-step procedures for full PRR activation $^{23,24}$, the requirement for a threshold PAMP concentration to achieve PRR activation ${ }^{25-28}$, amplification loops from initial low responses ${ }^{29}$ and numerous negative-feedback mechanisms $s^{30}$. One way in which the activation of PRR signalling in response to very low levels of PAMPs is avoided at the molecular level is through supramolecular organizing centres. These are higher-order signalling complexes at specific subcellular locations that rely on amplification mechanisms to achieve full activation, thus preventing signalling by subthreshold levels of PAMPs but amplifying signalling by superthreshold levels of PAMPs ${ }^{29}$. The double-edged sword-like nature of PRR-induced immune responses in terms of their roles in both protection and disease is also supported by evolutionary evidence. This includes the recurring loss of $2^{\prime}-5^{\prime}$-oligoadenylate synthase 1 (OAS1) in primates ${ }^{31}$. OAS1 is an interferon-inducible protein that is associated with both antiviral and pathological activities ${ }^{32,33}$. 


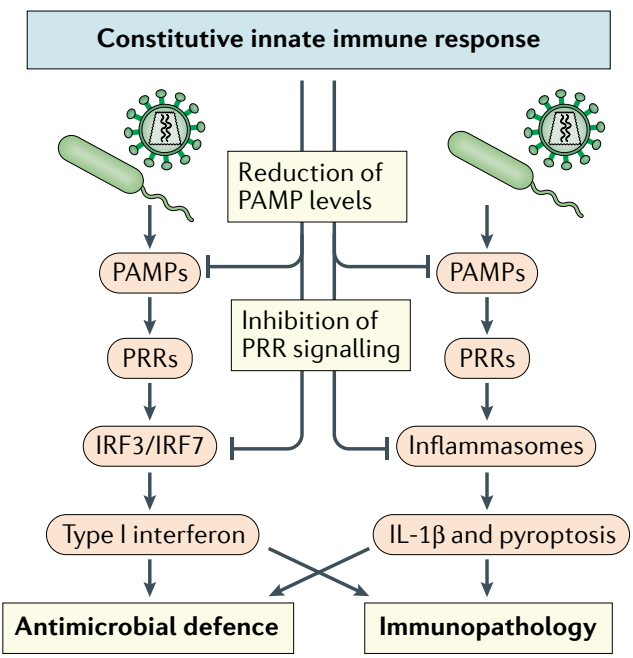

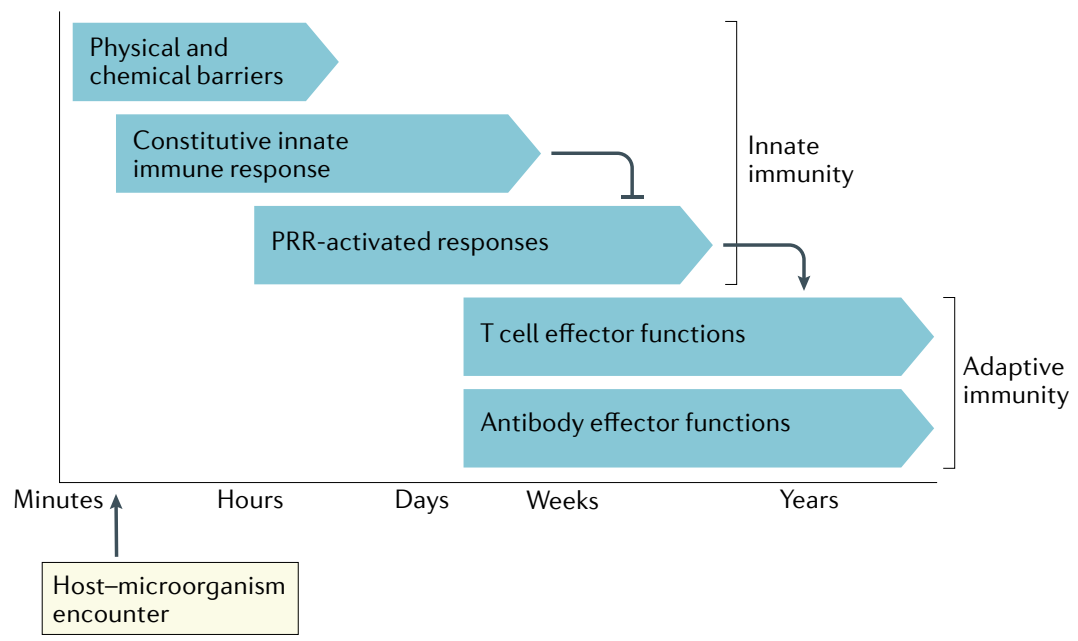

Fig. 2 | Constitutive innate immune responses negatively regulate inducible immune responses. a |Constitutive innate immune mechanisms eliminate pathogens during the initial stages of an infection, which prevents the accumulation of pathogen-associated molecular patterns (PAMPs) that would otherwise activate an inducible immune response through pattern recognition receptors (PRRs). In addition, many of the constitutive mechanisms are known to directly downregulate PAMP signalling through PRRs. Both of these effects limit PRR-induced expression of type I interferon and IL-1 $\beta$. $\mathbf{b}$ | The relationship between the different proposed layers of the immune response. A first layer of defence is

exerted by physical and chemical barriers. Constitutive innate immune mechanisms function as soon as a danger signal is detected and eliminate harmful microorganisms and host molecules by specific non-inflammatory mechanisms that operate independently of PRRs. This prevents establishment of the infection and accumulation of PAMPs, thus limiting the activation of PRR-based inducible innate immune responses. If PRR-based immunity is activated, owing to the level of PAMPs exceeding a certain threshold, this leads to inflammation and promotes activation of the adaptive immune response mediated by $T$ cells and antibodies. IRF, interferon regulatory factor.

Inducible mechanisms Biological processes that depend on the activation of transcriptional programmes and hence require intermediate steps between the trigger stimulus and effector function.

Supramolecular organizing centres

Location-specific higher-order signalling complexes, such as the myddosome in Toll-like receptor signalling, that amplify pattern recognition receptor signalling when pathogen-associated molecular pattern levels exceed specific threshold concentrations.

RNA interference (RNAi). The use of doublestranded RNA molecules containing sequences that match a given gene to knock down the expression of that gene by inhibiting translation of the targeted mRNA or by directing RNA-degrading enzymes to destroy the encoded mRNA transcript.
Constitutive innate immune mechanisms. Constitutive innate immune mechanisms respond to microbial activities, cellular stress and metabolic alterations by inducing antimicrobial effector functions. As there is most evidence for constitutive innate immune mechanisms that exert antiviral and antibacterial activities, these are the focus of this Review (FIG. 3). A large range of constitutive mechanisms of innate immunity have been identified, including restriction factors, antimicrobial peptides, basal autophagy and proteasomal degradation (BOX 2; TABLE 1). Here we divide these mechanisms into two classes: those that target specific steps in microbial replication cycles, such as restriction factors ${ }^{34,35}$, and those that lead to degenerative processes, such as autophagy ${ }^{9,36}$. The constitutive mechanisms that target specific steps in microbial replication function by blocking molecularly defined events that are essential for the replication of specific microorganisms but are dispensable for cellular fitness. By contrast, those mechanisms that operate through degenerative programmes target microbial or altered host molecules for recycling or degradation. The modes of action of representative examples from each of these mechanistic classes are described in the following sections.

Given the ability of constitutive immune mechanisms to exert antimicrobial activity, one consequence of their successful action is decreased levels of PAMPs (FIG. 2a). This, in turn, limits PRR activation and the downstream inflammatory response (FIG. 2b). Thus, constitutive immune mechanisms equip cells and tissues with a layer of defence that can fight infections immediately and hence potentially limit the requirement for inducible immune responses, such as type I interferon, IL-1 $\beta$ and other proinflammatory cytokines.

\section{Targeting microbial replication}

Direct inhibition of microbial replication is executed by molecules that interfere with specific steps in the replication cycle of a given microorganism. There are at least six mechanisms of action in this category: restriction factors that directly block a specific replication step; restriction factors that deplete molecules essential for replication; RNA interference (RNAi); antimicrobial peptides; soluble lectins; and metabolite-mediated inhibition of microbial replication (TABLE 1).

Restrictions factors. Restriction factors are antiviral proteins that target viral replication. Extensive studies, particularly of HIV-1 and herpesviruses ${ }^{37,38}$, have led to the identification of numerous restriction factors that together target nearly all steps in the viral replication cycle (FIG. 4a). For example, APOBEC3 proteins belong to the family of cytidine deaminases, which catalyse the deamination of cytidine to uridine in single-stranded DNA, thus introducing potentially deleterious mutations into the HIV-1 genome ${ }^{39}$. Likewise, tetherin is a membrane-bound protein that prevents the release of progeny HIV-1 particles from the cell surface ${ }^{40}$. These two mechanisms provide examples of direct blockade of specific steps in the replication cycle. By contrast, SAM domain and HD domain-containing protein 1 (SAMHD1) blocks HIV-1 replication indirectly, by converting deoxynucleoside triphosphates into inorganic phosphate and $2^{\prime}$-deoxynucleoside, 


\section{Box 1 | Diseases induced by excessive production of IL-1 and type I interferon}

Excessive or prolonged activation of pattern recognition receptor (PRR) signalling is associated with a range of human diseases. Several cytokines are involved in PRR-driven diseases, including tumour necrosis factor (TNF), IL-1 $1 \beta$, IL-6 and type I interferon ${ }^{169,170}$. Among these, IL-1 $\beta$ and type I interferon are induced exclusively by PRR signalling. Thus, the existence of human diseases that are mediated by these two classes of cytokines provides strong evidence for the pathological potential of PRR-based immune responses. Here we describe some examples of sterile inflammation involving IL-1 $\beta$ and type I interferon. We now know that diseases such as familial Mediterranean fever, TNF receptor-associated periodic syndrome, hyper-lgD syndrome and cryopyrin-associated periodic syndrome are characterized by increased expression of IL-1 $\beta$; furthermore, blocking IL-1-induced signalling in these disease can relieve clinical symptoms and improve disease outcome ${ }^{171}$. Similarly, diseases such as AicardiGoutières syndrome, stimulator of interferon gene (STING)-associated vasculopathy with onset in infancy, Sjögren syndrome, proteasome-associated autoinflammatory syndromes and systemic lupus erythematosus are associated with high levels of expression of interferon-stimulated genes (known as an 'interferon signature') and are termed 'interferonopathies', although the precise contribution of the interferon signature to disease pathogenesis is not completely understood ${ }^{170}$. For several of these diseases, inhibition of Janus kinase 1 (JAK1) and JAK3, which are involved in interferoninduced signalling, significantly reduces disease activity ${ }^{172}$. There are marked differences in the pathogenesis of IL-1-driven diseases and interferon-driven diseases. Diseases that depend on IL-1 are generally neutrophilic and associated with fever and increased levels of acute phase reactants, whereas interferon-driven diseases are characterized mainly by lymphopenia, vasculitis, central nervous system manifestations in some diseases, skin manifestations and varying levels of autoantibodies ${ }^{171,173}$.

thus depleting essential building blocks for HIV-1 reverse transcription ${ }^{34,41}$. The aforementioned restriction factors work in the plasma membrane or in the cytoplasm. However, many DNA viruses, including herpesviruses, replicate in the nucleus, where they are also targeted by numerous restriction factors. These include nuclear domain 10 bodies (ND10 bodies) and IFN $\gamma$-inducible protein 16 (IFI16), which operate by different mechanisms to epigenetically silence viral genomes $^{35,42}$. The herpesvirus DNA rapidly associates with ND10 bodies, which restrict viral gene expression by promoting processes that lead to the formation of nucleosome-like structures ${ }^{42}$. IFI16 restricts viral replication in the nucleus mainly by interfering directly with transcription $^{35}$. New evidence suggests that this involves the ability of IFI16 to form DNA filaments, which reduces recruitment of RNA polymerase II $\left(\mathrm{REF}^{43}\right)$, but also leads to recruitment of ND10 bodies, thus indicating that these two restriction systems might interact. The restriction factors discussed here are all constitutively expressed, although the expression of many of them is further increased by interferons $s^{35,44,45}$. Tonic type I interferon signalling or constitutive activity of interferon regulatory factor 1 (IRF1) drives the basal expression of many constitutive restriction factors ${ }^{8,46,47}$.

Nuclear domain 10 bodies (ND10 bodies). Membraneless, interchromatin structures in the nucleus of eukaryotic cells. ND10 bodies are made up mainly of proteins and have been described to be involved in a broad range of processes, including gene regulation, cell cycle, apoptosis, DNA repair and antiviral defence.
Caenorhabditis elegans and Drosophila melanogaster infected with Flock House virus activate antiviral defence mechanisms that depend on Dicer ${ }^{51,53}$. This constitutive immune mechanism might have a more important role in lower organisms, but as some mammalian viruses do target the RNAi system, there may be a subdominant role for this primordial antiviral system in host defence in more evolved organism ${ }^{54}$. For example, Ebola virus VP35 and VP30 proteins interact with Dicer cofactors, and the hepatitis $\mathrm{C}$ virus core protein directly associates with Dicer ${ }^{55,56}$.

Antimicrobial peptides. Antimicrobial peptides, including defensins and cathelicidins, contribute to the first line of defence against bacteria in the skin and at mucosal surfaces. They work by binding directly to bacterial membranes, thus perturbing membrane integrity and inhibiting microbial growth ${ }^{57-60}$. These peptides are rich in both cationic and hydrophobic amino acids, and generally form amphiphilic helical structures, although this may not be the case for all antimicrobial peptides ${ }^{61}$. This enables the peptides to interact with negatively charged bacterial surfaces through electrostatic interactions, thus triggering disruption of the bacterial membranes by pore-forming or non-pore-forming mechanisms ${ }^{62}$. Many antimicrobial peptides, such as $\beta$-defensin 1, are constitutively expressed on epithelial surfaces, thus providing immediate antimicrobial action on infection ${ }^{63}$. This is illustrated by the increased susceptibility to a broad range of bacterial infections in mice lacking cathelicidin antimicrobial peptide (CAMP) $)^{59,64}$. Beyond their role in antibacterial defence, there is also evidence that antimicrobial peptides can disrupt viral particles, thus exerting antiviral activity ${ }^{65,66}$. Similarly to the restriction factors, many antimicrobial peptides are expressed in both constitutive and inducible manners. This illustrates the general principle that different branches of the immune system can use overlapping effector functions (BOX 2).

Soluble lectins. Many microorganisms have extensive and more complex glycan patterns than mammalian cells, and these sugars can therefore be used as a means to distinguish self from non-self. There are four classes of soluble lectins carrying out this function, namely collectins, ficolins, galectins and pentraxins ${ }^{67}$. On recognition of non-self glycans, soluble lectins can exert host defence activities indirectly through complement activation and opsonization, as discussed later, or directly through aggregation and neutralization. For example, the collectin surfactant protein D (SP-D) has been reported to bind directly to highly glycosylated viruses such as HIV-1 and influenza A virus and neutralize their infectivity ${ }^{68,69}$. Similarly, pentraxin 3 directly binds influenza $A$ virus particles and neutralizes virus infectivity $^{70}$. Importantly, SP-D-deficient mice have impaired clearance of influenza A virus and increased production of proinflammatory cytokines in response to viral challenge ${ }^{71}$. In addition to viruses, SP-D also binds and agglutinates Streptococcus pneumoniae ${ }^{72}$, thus suggesting that soluble lectins might also have a role in the immediate inactivation of bacteria. 
Aerobic glycolysis

The process by which glucose is converted to lactate in the presence of oxygen to produce energy in the form of ATP.
Metabolite-mediated inhibition. A final example of constitutive immune mechanisms that directly interfere with microbial growth is provided by metabolites that block pathogen replication, and perhaps the best example of which is lactate ${ }^{73,74}$. Many viral infections are characterized by a shift of host cellular metabolism to aerobic glycolysis, which leads to the production of lactate $^{75,76}$. Viral infections also induce fatty acid synthesis and intermediate molecules in these pathways. These include palmitic acid and oleic acid, which have been shown to have antiviral activity ${ }^{77,78}$. The mechanisms by which lactate and other metabolites block viral replication remain to be determined, but the antiviral activity of lactate illustrates a general principle that select molecules accumulating during alterations of cellular homeostasis can interfere with microbial replication.

A second form of metabolite-dependent constitutive host defence is mediated through nutritional depletion and starvation of pathogens. For example, natural resistance-associated macrophage protein 1 (NRAMP1; also known as SLC11A1) is a metal ion transporter that transports divalent cations from vacuoles into the cytoplasm, hence depleting factors from vacuoles that are essential for the growth of intracellular pathogens ${ }^{79}$. The gene encoding NRAMP1 was shown to contribute to defence against, for example, Mycobacterium tuberculosis, Salmonella enterica subsp. enterica serovar Typhimurium and Leishmania donovani ${ }^{80,81}$, which was later shown to be mediated by the reduction of metal ion concentrations inside microorganism-containing vacuoles ${ }^{82}$. A second example of nutritional depletion is provided by lactoferrin, which is present in various secretory fluids. Lactoferrin is a highly cationic molecule that shows antimicrobial activity, in part, by binding and sequestering iron from pathogenic microorganisms ${ }^{83}$. Lactoferrin contributes to host defence in a non-redundant manner, as lactoferrin-deficient mice have increased susceptibility to Streptococcus mutans-induced dental caries, for example ${ }^{84}$.

\section{Degenerative mechanisms}

The second class of constitutive innate immune mechanisms functions through the degradation of danger molecules and elimination of unwanted cells. This class of mechanisms includes autophagy, phagocytosis, proteasomal degradation and nucleases (TABLE 1). Collectively, degenerative programmes function to continually limit danger signals, allowing for the rapid elimination of unwanted molecules without the activation of energy-consuming amplificative induced immune responses.

Autophagy and phagocytosis. Autophagy and phagocytosis execute the digestion of intracellular and extracellular microorganisms, respectively, through membrane encapsulation followed by chemical and enzymatic degradation $^{85,86}$. Pathogens are shunted into these pathways through the recognition of polyubiquitin chains or glycans inside damaged vacuoles in the case of autophagy $y^{9,87}$, and through complement coating of microorganisms in the case of phagocytosis ${ }^{88}$. In the case of autophagy, a large number of ubiquitin E3 ligases have been identified that coat viral and bacterial surfaces with ubiquitin ${ }^{9,89-92}$, thus targeting microorganisms for loading into autophagosomes through interaction with the autophagosome-associated protein LC3 (also known as MAP1ALC3) ${ }^{85}$ (FIG. 4b). This targeting mechanism involves E3 ligases, including SMURF1 and LRSAM1 $\left(\right.$ REFS $\left.^{91,92}\right)$, as well as the ubiquitin-binding selective autophagy receptors p62 (also known as SQSTM1), optineu-

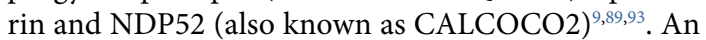
alternative mechanism for sensing of vesicle-damaging pathogens has been identified that involves damaged vesicles exposing glycans in the cytoplasm for sensing by galactin 8, which links to autophagy via NDP52 (REF. ${ }^{87}$ ). This triggers phagophore formation in the vicinity of cytosolic bacteria ${ }^{94}$. Autophagy has important roles in the control of infection. For example, defective autophagy leads to increased susceptibility to infection with Sindbis virus in mice ${ }^{89}$. In addition, stimulation of autophagy in primary human macrophages mediated protection against $M$. tuberculosis infection ${ }^{95,96}$. However, mice defective in autophagy do not have impaired antimycobacterial defence in vivo, which indicates that the precise role of autophagy requires further investigation ${ }^{97}$. Third, herpes simplex virus type 1 specifically interferes with autophagy, which is essential for neuropathogenicity of the virus ${ }^{36}$.

Complement-mediated phagocytosis involves specific recognition of complement components bound to the surface of microorganisms by the corresponding complement receptors on phagocytes. Activation of the complement system, for example after sensing of glycans by the lectin pathway, leads to the formation of $\mathrm{C} 3$ convertase, eventually generating $\mathrm{C} 3 \mathrm{~b}$, which binds to complement receptors, thus inducing phagocytosis ${ }^{98}$. Mice devoid of the lectin-based complement pathway have increased susceptibility to Staphylococcus aureus infection and impaired bacterial phagocytosis ${ }^{99}$. Furthermore, several bacteria, including Streptococcus pyogenes, inhibit complement-mediated phagocytosis ${ }^{100}$.

A third degenerative mechanism for the degradation of membrane-encapsulated extracellular material is LC3-associated phagocytosis (LAP), which uses components from both the phagocytosis and autophagy pathways ${ }^{101}$. LAP is involved in the clearance of extracellular pathogens and dead cells ${ }^{102}$, and LAP-deficient mice fail to clear Aspergillus fumigatus infection ${ }^{103}$. Thus, autophagy, phagocytosis and LAP are important systems for immediate host defence.

Proteasomal degradation. The proteasome is a cytoplasmic protein complex that degrades proteins by proteolysis ${ }^{104}$. Proteins to be degraded are tagged by K48-linked polyubiquitylation, attracted to the proteasome, unfolded into polypeptides and then degraded ${ }^{104}$. The proteasomal degradation pathway also contributes to immediate defence against infecting pathogens. For example, viruses can be detected by the ubiquitin E3 ligase TRIM21 through binding to antibody-bound viral capsids, which links to downstream proteasomal degradation ${ }^{105}$. This process is involved in the elimination of infecting viral capsids from the cytoplasm and contributes to antiviral defence ${ }^{105-107}$. Other studies have shown that the viral RNA-dependent RNA polymerase of 
a Viral infection
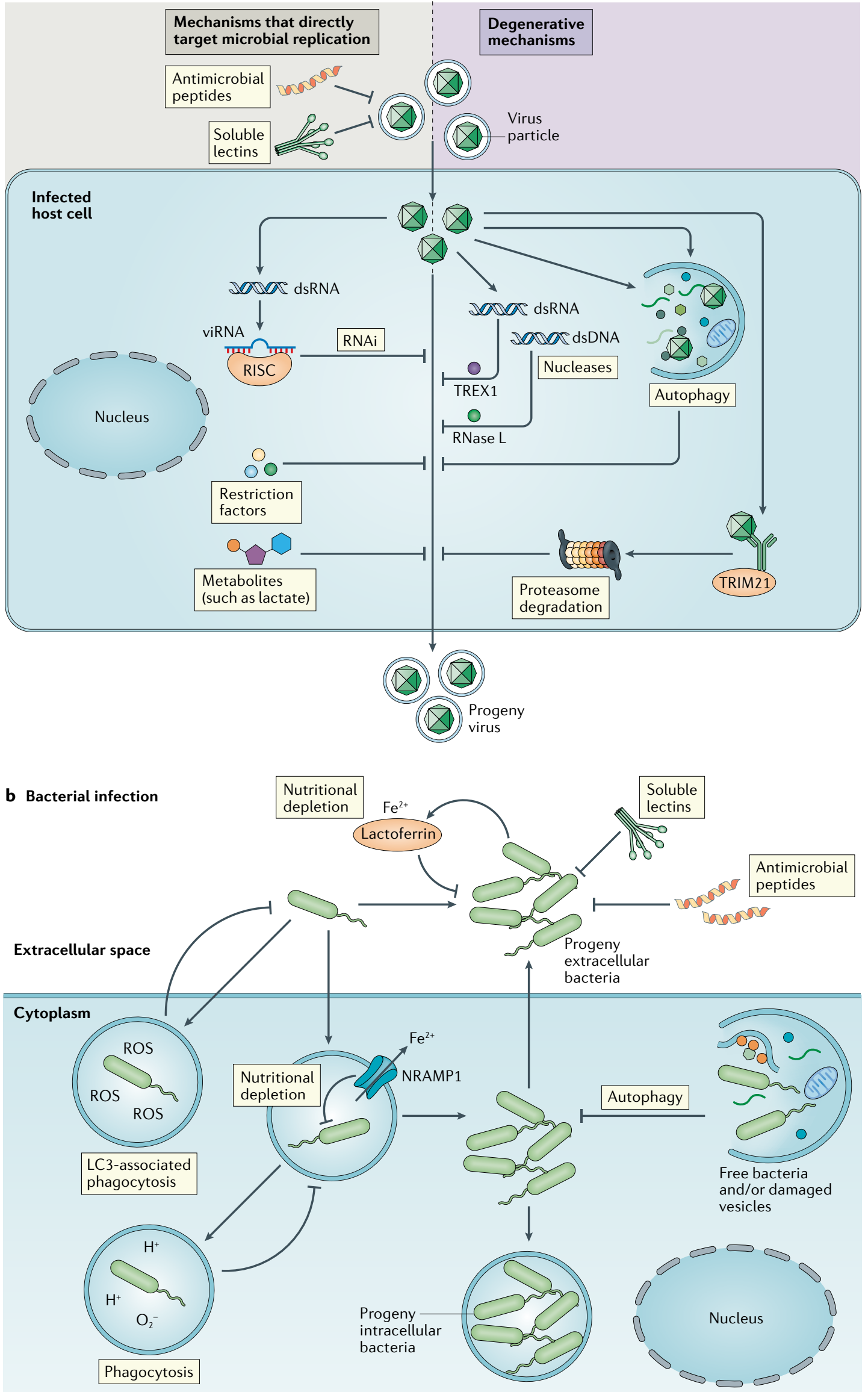
4 Fig. 3 | Overview of the regulation of microbial replication by constitutive innate immune mechanisms. a Constitutive innate immune mechanisms and viral infection. The accumulation of specific viral molecular structures (such as double-stranded RNA (dsRNA) or capsids) and cellular stress responses (such as autophagy) activate constitutive-latent mechanisms with direct antiviral activity, independently of pattern recognition receptors. Some of the antiviral effector functions target microbial replication by blocking specific steps in the replication cycles of viruses; these effectors include soluble lectins, antimicrobial peptides, restriction factors, RNA interference (RNAi) and metabolites. Other antiviral effectors of the constitutive response function through the degradation of virus particles; these include nucleases such as TREX1, which degrades viral DNA in the cytoplasm, and RNase L, which degrades viral RNA, as well as autophagy and proteasomal degradation. Viruses can be targeted for proteasomal degradation by the ubiquitin E3 ligase TRIM21, which binds to antibody-attached viral capsids. $\mathbf{b} \mid$ Constitutive innate immune mechanisms and bacterial infection. The presence of bacteria changes the local microenvironment, for example through the accumulation of hydrophobic and charged bacterial surfaces or alteration of cellular metabolism. This activates antibacterial activities independently of pattern recognition receptors, including inactivation by soluble lectins and antimicrobial peptides, nutritional depletion by natural resistance-associated macrophage protein 1 (NRAMP1) and lactoferrin, and bacterial degradation by phagocytosis and basal autophagy. dsDNA, double-stranded DNA; RISC, RNA-induced silencing complex; ROS, reactive oxygen species; viRNA, virus-derived small interfering RNA.

cGAS-STING pathway (Cyclic GMP-AMP synthasestimulator of interferon genes pathway). cGAS is a cytosolic DNA-sensing pattern recognition receptor that signals via STING to induce the expression of type I interferon and inflammatory cytokines.

RIG-I-MAVS pathway (Retinoic acid-inducible gene I protein-mitochondrial antiviral signalling protein pathway). RIG-I is a cytosolic RNA-sensing pattern recognition receptor that signals via MAVS to induce the expression of type I interferon and inflammatory cytokines. turnip yellow mosaic virus is degraded by the ubiquitinproteasome pathway to control infection ${ }^{108}$. Proteasome activity also contributes to defence against many bacterial infections, including Yersinia spp. infections ${ }^{109}$, and the ubiquitin-proteasome pathway is targeted by many viruses and bacteria to promote replication ${ }^{110-114}$. For example, the human cytomegalovirus protein pUL25 inhibits proteasomal degradation of another viral protein, pUL26, to sustain the activity of a pUL26-mediated immune evasion mechanism ${ }^{114}$. Collectively, these examples show that the conserved proteasome pathway is part of the constitutive immune defence repertoire.

Nucleases. The cytoplasm contains RNAses and DNAses that eliminate unwanted nucleic acid species, including viral nucleic acids, and these enzymes can thereby contribute to sterilization of the cytoplasm. RNase L is a latent cytoplasmic exoribonuclease that is activated by $2^{\prime}-5^{\prime}$ oligoadenylates produced by OASs ${ }^{115}$. Although OASs are highly interferon inducible, they are also expressed at a basal level and hence induce basal RNase L activity ${ }^{116}$. Importantly, this activity has been suggested to contribute to basal restriction of coronaviruses in myeloid cells, and hence to protect other cell types from infection ${ }^{117}$. TREX1 is a cytoplasmic exodeoxyribonuclease that eliminates DNA from the cytoplasm. Very few microorganisms have free DNA as part of their productive replication cycle, but exogenous and endogenous retroviruses have a cytoplasmic DNA step that is sensitive to degradation by TREX1. Consequently, Trex $1^{-/-}$mice have increased levels of endogenous retroviral DNA in the cytoplasm ${ }^{118}$, which indicates that TREX1 has a role in limiting retroviral infection and hence maintaining genome integrity.

\section{Limiting inflammatory responses}

Immune responses induced by PRRs and by antigenspecific receptors are often highly potent and sterilizing. However, they may also be relatively disruptive and can be associated with tissue damage and the requirement for significant tissue repair and energy consumption ${ }^{119}$. Many of the constitutive immune mechanisms discussed here not only interfere with microbial replication but also have negative effects on PRR activity (TABLE 1). This raises the possibility that an overarching function of the constitutive immune mechanisms is to both eliminate danger and limit the use of PRR-driven activities. At the mechanistic level, this immunoregulatory function of the constitutive mechanisms can be exerted in two qualitatively different ways. The first is through the direct effect of their antimicrobial activity on decreasing levels of PAMPs. The second is through specific inhibition of PRR signalling.

Reduction of PAMP levels. Many studies have shown that PRR activation requires PAMP levels to be above a certain threshold ${ }^{25-28}$. Above this threshold, PRRs are activated in a concentration-dependent manner until saturation is reached. Therefore, constitutive immune mechanisms that reduce PAMP levels will limit or even prevent PRR activation (FIG. 2a). For example, mice deficient in the restriction factor APOBEC3, which has antiretroviral activity, have higher viral loads after infection with murine leukaemia virus and corresponding higher levels of reverse viral transcripts and downstream interferon induction through the CCAS-STING pathway (cyclic GMP-AMP synthase-stimulator of interferon genes pathway $)^{120}$. Similarly, SAMHD1 activity in vivo controls lentivirus load and limits virus-induced production of interferons in myeloid cells ${ }^{121}$. In addition, SAMHD1 deficiency leads to increased expression of costimulatory molecules and T cell activation on lentiviral infection, which suggests that the constitutive reduction of PRR activation by SAMHD1 limits not only the expression of innate immune cytokines but also downstream adaptive immune responses ${ }^{121}$. A third example is provided by the observation that expression of Drosophila Dicer in mammalian cells leads to decreased induction of IFN $\beta$ by double-stranded RNA, most likely owing to the digestion of immunostimulatory RNA into shorter 20-25-bp RNA species that activate PRRs only inefficiently ${ }^{122}$. Finally, constitutive innate immune mechanisms can also reduce PRR activity by lowering the concentration of PAMPs that have immunostimulatory activity. For example, lactoferrin binds CpG DNAs and inhibits their ability to activate TLR9 (REF. ${ }^{123}$ ).

Inhibition of PRR signalling. In addition to reducing the levels of PAMPs, some constitutive mechanisms have been reported to target PRR activity at the signalling level (FIC. 2a). For example, autophagy negatively regulates signalling by the RIG-I-MAVS pathway (retinoic acid-inducible gene I protein-mitochondrial antiviral signalling protein pathway) and by the cGAS-STING pathway; in the former case by limiting reactive oxygen species-mediated amplification of signalling and by LC3-dependent MAVS inactivation ${ }^{124,125}$, and in the latter case through degradation of STING ${ }^{126}$. In line with this, defective autophagy as a result of ATG16L deficiency predisposes to STING-dependent intestinal pathology in mice ${ }^{127}$, and ATG5 deficiency selectively in 


\section{Box 2 | Overlap between constitutive and inducible immune responses}

In most respects, constitutive and inducible immune responses operate through different principles; however, in certain cases, their downstream effector activities may overlap. This is to be expected given that all of these responses use mechanisms from the same 'evolutionary toolbox' to achieve optimal protection of the host. For example, autophagy can be activated during infection and upon sterile danger ${ }^{9,174}$. Similarly, phagocytosis can be activated by both Toll-like receptor (TLR)-dependent and TLRindependent mechanisms ${ }^{175-177}$. Moreover, many restriction factors are expressed at basal levels to exert immediate antiviral activity, but are also induced transcriptionally in response to stimulation with type I interferon ${ }^{35,40,178}$. Nevertheless, despite these minor areas of overlap between constitutive immune mechanisms and the pattern recognition receptor (PRR)-induced immune responses, the differences are more pronounced. The key difference between constitutive immune mechanisms and PRRinduced immunity is that the former mechanisms are all activated through pre-existing molecules to directly eliminate danger, whereas the latter system functions mainly through inducible transcription-dependent proinflammatory programmes. In addition, inducible innate responses can amplify adaptive responses, whereas constitutive innate responses do not amplify inducible innate responses.

neutrophils exacerbates $M$. tuberculosis immunopathology without affecting bacterial load ${ }^{97}$. As a second example, lactate, which is produced during aerobic glycolysis and has virus-restricting activity ${ }^{73,74}$, also directly inhibits MAVS activity; thus lactate both reduces levels of viral PAMPs and has a negative regulatory function to inhibit PAMP-driven signalling and interferon expression ${ }^{128}$. Third, an engineered amphipathic-helical antimicrobial peptide was found to block TLR4 signalling through the TRIF pathway ${ }^{129}$. This occurs by the inhibition of TLR4 endocytosis, which is an essential step for the engagement of TRIF from endosomal compartments.

Collectively, the current literature suggests that constitutive immune mechanisms reduce PRR activation through a range of mechanisms and, therefore, that these constitutive mechanisms impose a threshold and negative regulatory activity on the amplificative innate and adaptive immune responses (FIG. 2b). We propose that rapid, molecularly specific and non-amplificative responses to challenges provided by constitutive immune mechanisms are beneficial for achieving optimal host defence with minimal immunopathology.

\section{Constitutive immunity beyond infection}

Our main focus here has been on infections. However, constitutive immune mechanisms are also involved in the elimination of sterile danger. For example, DNA damage in the nucleus and the accumulation of DNA in extranuclear compartments are eliminated by the DNA damage response and specific DNases ${ }^{130}$, respectively; the accumulation of misfolded proteins leads to the formation of aggresomes, which are cleared by selective autophagy ${ }^{131,132}$; excessive accumulation of reactive oxygen species leads to death of the oxygen-stressed cells ${ }^{133}$; and free cholesterol is converted into an ester derivative by lecithincholesterol acyltransferase, thus enabling transport to the liver by high-density lipoprotein and eventual degradation ${ }^{134}$. Defects in these constitutive and latent danger-eliminating mechanisms lead to the accumulation of danger-associated molecular patterns and activation of PRR-based immunity. For example, in cells with defects in either the DNA damage response or extranuclear DNases, the accumulation of DNA induces type I interferon production through the cGAS-STING pathway ${ }^{135-138}$. Similarly, defective elimination of protein aggregates or cholesterol leads to the induction of IL- $1 \beta$ production through activation of the NLRP3 inflammasome ${ }^{139,140}$. Common to all of the examples given above is that the accumulated abnormal endogenous molecules are detected and eliminated through molecularly specific mechanisms independently of PRRs. This elimination limits PRR activation and hence inflammatory reactions. Therefore, in addition to eliminating microorganisms and PAMPs, constitutive immune mechanisms also eliminate sterile danger signals in a damage-limiting manner that prevents the activation of excessive inflammation.

\section{Constitutive immunity in human health}

We propose that constitutive immune mechanisms enable cells and organisms to fight infections and eliminate endogenous abnormalities in a non-inflammatory manner. Therefore, an important benefit of these mechanisms may be to increase the threshold for development of clinically overt signs of disease on exposure to infections or endogenous danger. Studies of the associations between single-nucleotide polymorphisms and infections have shown that restriction factors, antimicrobial peptides and autophagy have important roles in antimicrobial defence ${ }^{141-144}$. Constitutive immune mechanisms may be particularly active in the protection of tissues that are frequently exposed to pathogens, such as epithelial cells in the airways and the gut, or tissues that are particularly vulnerable to immunopathology, such as the brain. In favour of this idea, RNA lariat debranching enzyme 1 (DBR1) and small nucleolar RNA, H/ACA box 31 (SNORA31) were recently shown to have non-redundant, interferon-independent roles in the prevention of viral brainstem encephalitis and herpes simplex encephalitis, respectively ${ }^{11,12}$. The mechanisms through which they exert their antiviral activity remain to be determined. Reports have shown that autophagy is an antiviral mechanism in the brain in mice ${ }^{36,89,145}$. In addition, some cell populations, including stem cells, seem to use constitutive immune mechanisms to eliminate danger without losing key functions, such as self-renewal and differentiation capacity, that are known to be impaired by PRR-based immunity $^{146,147}$.

An important question related to human immunology is how individuals with a loss-of-function mutation in a constitutive immune mechanism may present clinically. Deficiency of a mechanism that is expressed in specific organs or cell types might lead to a higher frequency of clinical infections by a subset of microorganisms that are normally controlled by the defective mechanism. This seems to be the case for defects in DBR1, which confer susceptibility to disease caused by infections with herpes simplex virus type 1 , influenza virus or norovirus in the brainstem ${ }^{11}$. The impact of deficiencies in constitutive immune mechanisms might not be limited to acute infections and could also include chronic and latent infections. In support of a link between such defects and increased inflammation, patients with inborn defects in DNA repair, elimination of extranuclear DNA or degradation of misfolded proteins develop autoinflammatory 
diseases, including Aicardi-Goutières syndrome and proteasome-associated autoinflammatory syndromes, which are characterized by type I interferon-dependent autoinflammation and are termed interferonopathies ${ }^{\prime 137,148-150}$. Therefore, a loss of function in constitutive immune mechanisms can lead to selective susceptibility to specific infections or to infections in specific organs. Likewise, such deficiency might lead to the accumulation of PAMPs, microorganism-associated molecular patterns, danger-associated molecular patterns and/or

Table 1 | Constitutive immune mechanisms in host defence

\begin{tabular}{|c|c|c|c|c|c|}
\hline $\begin{array}{l}\text { Type of } \\
\text { effector }\end{array}$ & Examples & Trigger & Target microorganisms & $\begin{array}{l}\text { Evidence for control of } \\
\text { inflammatory responses }\end{array}$ & Refs \\
\hline \multicolumn{6}{|c|}{ Targeting microbial replication } \\
\hline \multirow[t]{2}{*}{$\begin{array}{l}\text { Restriction } \\
\text { factors }\end{array}$} & BST2, YBX1, IFITMs & $\begin{array}{l}\text { Specific viral } \\
\text { replication events }\end{array}$ & HIV-1, HCV, HSV-1, VSV, RSV & $\begin{array}{l}\text { Increased IL- } 6 \text { and IL-1 } \beta \text { expression } \\
\text { in the lungs of RSV-infected Ifitm } 1^{-/-} \\
\text {mice; increased constitutive infiltration } \\
\text { of monocytes and macrophages in the } \\
\text { kidney in } Y b \times 1^{-/-} \text {mice }\end{array}$ & $\begin{array}{r}40,44, \\
154-156\end{array}$ \\
\hline & SAMHD1, APOBEC3 & $\begin{array}{l}\text { Modulation of nucleic } \\
\text { acid availability and/or } \\
\text { function }\end{array}$ & $\begin{array}{l}\text { HIV-1, vaccinia virus, } \mathrm{HSV}-1 \text {, } \\
\text { murine herpesvirus } 68 \\
\text { parvovirus }\end{array}$ & $\begin{array}{l}\text { Increased spontaneous and } \\
\text { lentivirus-induced interferon and } \\
\text { ISG expression in Samhd } 1^{-/-} \text {mice; } \\
\text { increased IFN } \beta \text { expression in } \\
\text { Apobec } 3^{-/} \text {mice infected with murine } \\
\text { leukaemia virus }\end{array}$ & $\begin{array}{r}39,41,120, \\
121,157,158\end{array}$ \\
\hline RNAi & RISC & dsRNA & $\begin{array}{l}\text { Cucumovirus (plants), Flock } \\
\text { House virus (worms), cricket } \\
\text { paralysis virus (flies) }\end{array}$ & $\begin{array}{l}\text { Introduction of Drosophila Dicer-2 } \\
\text { in mammalian cells reduced } \\
\text { dsRNA-induced IFN } \beta \text { expression }\end{array}$ & $50-52,159$ \\
\hline $\begin{array}{l}\text { Antimicrobial } \\
\text { peptides }\end{array}$ & $\begin{array}{l}\beta \text {-Defensins, } \\
\text { cathelicidin }\end{array}$ & $\begin{array}{l}\text { Negatively charged } \\
\text { surfaces }\end{array}$ & $\begin{array}{l}\text { Salmonella enterica subsp. } \\
\text { enterica serovar Typhimurium, } \\
\text { Escherichia coli, Shigella spp., } \\
\text { HIV-1 }\end{array}$ & $\begin{array}{l}\text { LL37 inhibits DNA-sensing } \\
\text { inflammasomes in psoriatic skin; } \\
\text { an engineered antimicrobial peptide } \\
\text { inhibits TLR4 signalling through } \\
\text { the TRIF pathway }\end{array}$ & $\begin{array}{r}58-60,65 \\
129,160\end{array}$ \\
\hline Soluble lectins & $\begin{array}{l}\text { Collectins, ficolins, } \\
\text { galectins, pentraxins }\end{array}$ & Glycans & $\begin{array}{l}\text { HIV-1, influenza A virus, } \\
\text { Streptococcus pneumoniae }\end{array}$ & $\begin{array}{l}\text { SP-A inhibits LPS-induced TLR4 } \\
\text { activation by preventing the } \\
\text { interaction with LPS-binding protein; } \\
\text { SP-D-deficient mice have increased } \\
\text { levels of proinflammatory cytokines } \\
\text { after influenza virus infection }\end{array}$ & $68-72,161$ \\
\hline \multirow[t]{2}{*}{ Metabolites } & Lactate, palmitic acid & Metabolic alterations & HIV-1, HSV-1, Zika virus, VSV & $\begin{array}{l}\text { Ldha }{ }^{-/-} \text {mice express increased levels of } \\
\text { type I interferon on infection with RNA } \\
\text { viruses }\end{array}$ & $\begin{array}{r}73,74,77, \\
162,163\end{array}$ \\
\hline & NRAMP1, lactoferrin & Iron depletion & $\begin{array}{l}\text { Mycobacterium tuberculosis, } \\
\text { S. Typhimurium, Leishmania } \\
\text { donovani, Streptococcus } \\
\text { mutans }\end{array}$ & $\begin{array}{l}\text { Lactoferrin binds CpG DNA and } \\
\text { impedes stimulation through TLR9 }\end{array}$ & $\begin{array}{r}80,81 \\
84,123\end{array}$ \\
\hline \multicolumn{6}{|c|}{ Degenerative mechanisms } \\
\hline Autophagy & - & $\begin{array}{l}\text { Viral proteins, } \\
\text { organelle dysfunction, } \\
\text { protein aggregates }\end{array}$ & $\begin{array}{l}\text { M. tuberculosis, } \\
\text { S. Typhimurium, Sindbis virus }\end{array}$ & $\begin{array}{l}\text { Increased interferon expression } \\
\text { and inflammasome activation in } \\
\text { autophagy-defective cells; excess IL-1 } \\
\text { production and lung inflammation } \\
\text { in autophagy-deficient mice after } \\
\text { infection and sterile challenge }\end{array}$ & $\begin{array}{l}9,89,96 \\
126,164\end{array}$ \\
\hline Phagocytosis & - & Opsonization & $\begin{array}{l}\text { Staphylococcus aureus, } \\
\text { Salmonella spp., Mycobacteria } \\
\text { spp., Aspergillus spp. }\end{array}$ & $\begin{array}{l}\text { Patients with CGD have increased } \\
\text { inflammasome activity and IL-1 } \beta \\
\text { production }\end{array}$ & 165,166 \\
\hline $\begin{array}{l}\text { LC3-associated } \\
\text { phagocytosis }\end{array}$ & - & Not known & $\begin{array}{l}\text { S. Typhimurium, Listeria } \\
\text { monocytogenes, Burkholderia } \\
\text { pseudomallei }\end{array}$ & $\begin{array}{l}\text { LC3-deficient mice fail to clear } \\
\text { dead cells and develop lupus-like } \\
\text { inflammatory disease }\end{array}$ & $\begin{array}{l}102,123 \\
167,168\end{array}$ \\
\hline $\begin{array}{l}\text { Proteasomal } \\
\text { degradation }\end{array}$ & - & $\begin{array}{l}\text { Cytosolic capsids and } \\
\text { capsid-lgG complexes }\end{array}$ & $\begin{array}{l}\text { Adenovirus, turnip yellow } \\
\text { mosaic virus }\end{array}$ & $\begin{array}{l}\text { Patients with PRAAS-associated } \\
\text { mutations in proteasome genes have } \\
\text { strong interferon signatures }\end{array}$ & $\begin{array}{r}105-107, \\
111,148,149\end{array}$ \\
\hline $\begin{array}{l}\text { Nucleic acid } \\
\text { degradation }\end{array}$ & - & $\begin{array}{l}\text { Cytosolic RNA } \\
\text { and DNA }\end{array}$ & $\begin{array}{l}\text { Endogenous retroviruses, } \\
\text { murine coronaviruses }\end{array}$ & $\begin{array}{l}\text { Patients with defective TREX } 1 \text { have } \\
\text { increased interferon expression and } \\
\text { develop Aicardi-Goutières syndrome }\end{array}$ & $117,118,137$ \\
\hline
\end{tabular}

APOBEC3, apolipoprotein B mRNA-editing complex 3; BST2, bone marrow stromal antigen 2 (also known as tetherin); CGD, chronic granulomatous disease; dsRNA, double-stranded RNA; HCV, hepatitis C virus; HSV-1, herpes simplex virus type 1; IFITMs, interferon-induced transmembrane proteins; ISG, interferon-stimulated gene; Ldha, lactate dehydrogenase A; LPS, lipopolysaccharide; NRAMP1, natural resistance-associated macrophage protein 1; PRAAS, proteasome-associated autoinflammatory syndromes; RISC, RNA-induced silencing complex; RNAi, RNA interference; RSV, respiratory syncytial virus; SAMHD1, SAM domain and HD domain-containing protein 1; SP, surfactant protein; TLR, Toll-like receptor; VSV, vesicular stomatitis virus; YBX1, Y-box binding protein 1. 
a Restriction factors
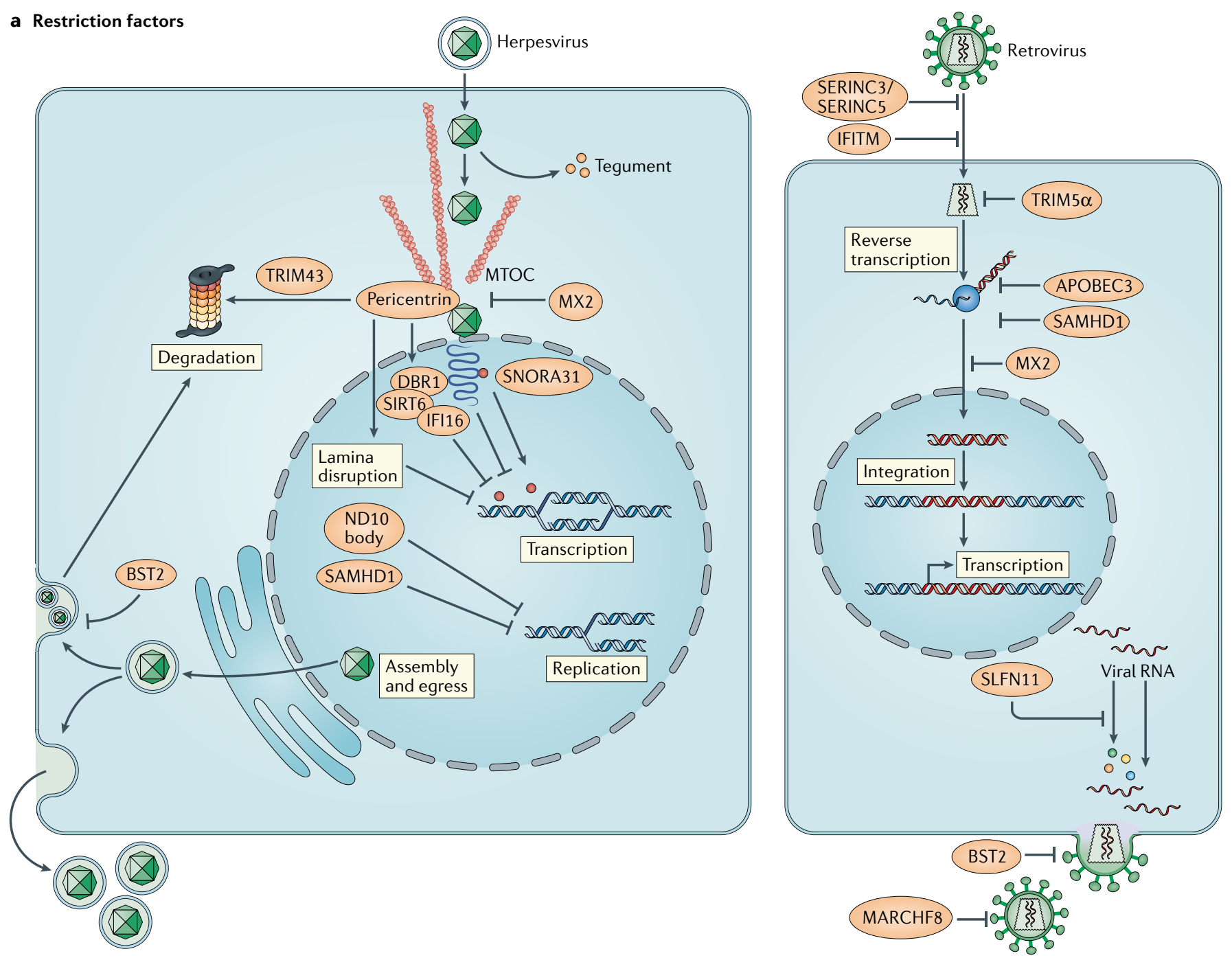

b

SMURF1
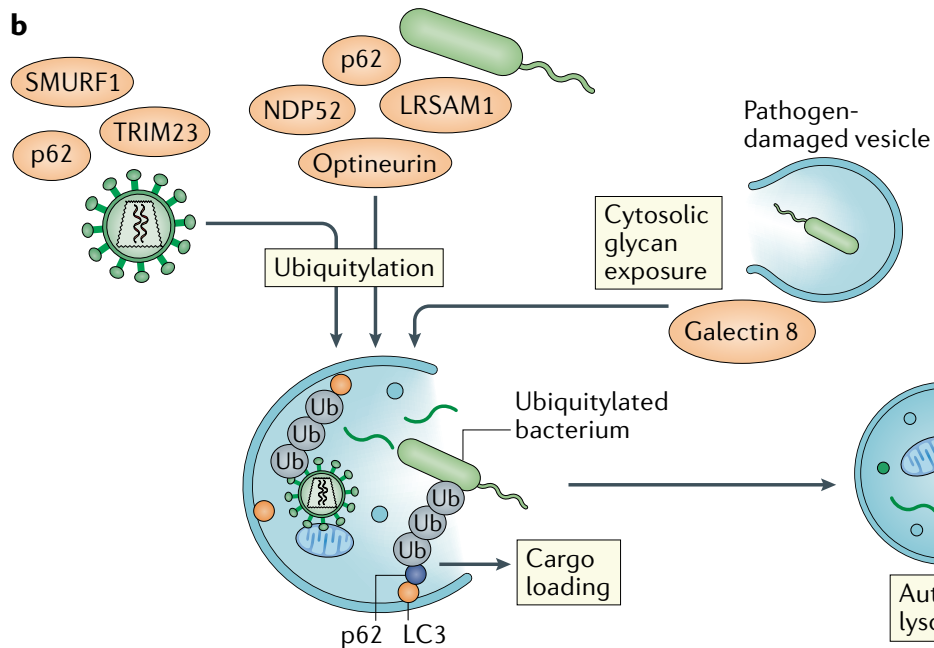

Pathogendamaged vesicle
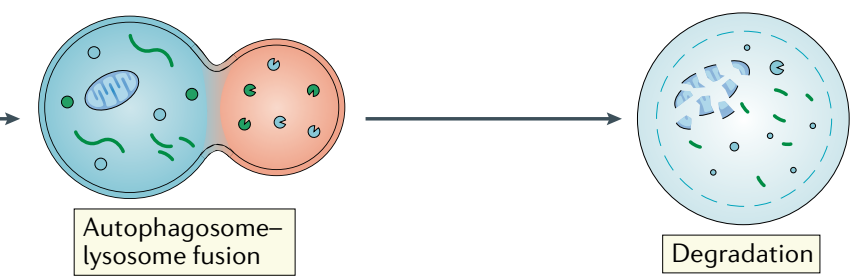

Fig. 4 | Constitutive control of microbial replication by restriction factors and autophagy. a $\mid$ Restriction factors that control herpesvirus and retrovirus infections, including their targets in the viral replication cycle. Restriction factors interfere with viral replication by either blocking a specific and essential step in the viral replication cycle (for example, viral gene transcription or release of progeny virus) or depletion of factors that are essential for replication (such as deoxynucleoside triphosphates). b | Blockade of viral and bacterial replication by autophagy. Various ubiquitin E3 ligases (such as SMURF1, LRSAM1 and TRIM23) and ubiquitin-binding proteins (such as p62, optineurin and NDP52) have been identified to conjugate ubiquitin to microbial surfaces, which targets them for loading into autophagosomes. Also, cytosolic exposure of glycans by pathogen-damaged vesicles can be recognized by galectin 8 for targeting to autophagosomes. APOBEC3, apolipoprotein B mRNA-editing complex 3; BST2, bone marrow stromal antigen 2 (also known as tetherin); DBR1, RNA lariat debranching enzyme 1; IFI16, interferon- $\gamma$-inducible protein 16; IFITM, interferon-induced transmembrane protein; MTOC, microtubule-organizing centre; ND10, nuclear domain 10; SAMHD1, SAM domain and HD domain-containing protein 1; SIRT6, sirtuin 6; SNORA31, small nucleolar RNA, H/ACA box 31. 


\section{NRF2-KEAP}

Nuclear factor erythroid 2-related factor 2 (NRF2) senses oxidative stress, whereupon it is released from Kelch-like ECH-associated protein 1 (KEAP1) to translocate to the nucleus and induce gene expression.

Hypoxia-inducible factor $1 \alpha$ A transcription factor that is activated by hypoxia to induce the expression of genes with hypoxia-responsive elements in their promoters.

Bone morphogenetic protein-SMAD

Bone morphogenetic proteins are growth factors that signal through SMAD proteins to induce gene transcription.

\section{Box 3 | A new concept of damage-limiting immune mechanisms?}

In addition to the constitutive immune mechanisms described in this Review, several pathways are activated in response to infections and sterile challenge that function independently of pattern recognition receptors (PRRs) and antigen-specific receptors to control infection. These include the NRF2-KEAP1, hypoxia-inducible factor $1 a$ and bone morphogenetic protein-SMAD pathways ${ }^{10,151-153}$. These pathways differ from the constitutive immune mechanisms by engaging transcriptional programmes to execute their activities ${ }^{10,151-153}$. Some of these pathways have also been reported to exert negative control of PRR signalling ${ }^{151,152,179,180}$, which shows that they share both antimicrobial and immunoregulatory functions with the constitutive immune mechanisms. For example, NRF2-deficient mice have increased susceptibility to certain viral infections ${ }^{152}$, and NRF2 also negatively regulates cyclic GMP-AMP synthase (cGAS)-stimulator of interferon gene (STING) signalling ${ }^{180}$. As we gain more information about the actions of constitutive immune mechanisms and PRR-independent transcriptional pathways in early host defence, we believe that the immunological community should consider whether these diverse mechanisms share features that distinguish them from other immune pathways. It is possible that the constitutive immune mechanisms described in this Review are part of a larger group of damage-limiting immune mechanisms that can be defined by fulfilling all of the following criteria:

1. Function independently of PRRs and antigen-specific receptors

2. Respond to the presence of specific microbial or host stress-related molecules

3. Eliminate danger in a non-inflammatory manner, and limit PRR activation by removing PRR ligands and/or inhibiting PRR signalling

4. Eliminate danger through specific effector functions that target defined host or microbial structures and activities

Whereas the physical and chemical barrier functions of the immune system fulfil criteria 1 and 3 , they do not satisfy criteria 2 and 4 . Similarly, PRRs and antigen-specific receptors fulfil criteria 2 and 4 , but do not fulfil criteria 1 and 3 . Although it is speculative at present, we think that the idea of damage-limiting immune mechanisms may serve as a useful guide for future experimental and clinical research.

homeostasis-altering molecular processes and associated pathological inflammation (BOX 1).

\section{Outlook}

In this article, we have described the role and mode of action of a large panel of constitutive mechanisms used by the immune system to exert immediate control of infections and endogenous dangers independently of the inducible mechanisms that are activated through PRRs and antigen-specific receptors. Although many such constitutive responses have been known for years, greater understanding of the mechanisms involved and renewed interest in fields such as restriction factor biology and immunometabolism are spurring further work in the area. With the identification of constitutive mechanisms that have non-redundant roles in host defence, we now know that these immune mechanisms are not just redundant, non-specific players in immunology $y^{11,12}$. This should stimulate interest in understanding the roles played by constitutive immune mechanisms in host defence in vivo, which might include the identification of new primary immune disorders. Improved knowledge of the host cell type and tissue specificities of constitutive immune mechanisms in relation to susceptibility to infections could greatly improve our understanding of human immunology. Such work will start to provide answers to the fundamental question of how the immune system determines the degree of threat caused by an infection and balances that with the appropriate strength of the immune reaction.

Finally, as we gain further insights into the various host responses that are activated during immunological challenge, it will be interesting to explore the idea that the immune system has a defensive layer of activities that have been selected to eliminate danger without engaging the PRR system (BOX 3). In this respect, it is interesting to note that in addition to the constitutive mechanisms described in this Review, there are various sensing systems that use transcriptional programmes to induce host defence independently of PRRs and with the ability to control inflammation. They include the NRF2-KEAP 1 , hypoxia-inducible factor $1 \alpha$ and bone morphogenetic protein-SMAD pathways ${ }^{10,151-153}$. In addition, the constitutive host defence exerted by commensal bacteria through several mechanisms, including niche competition, warrants more attention. With more and more data emerging on the importance of constitutive mechanisms in immunology, there is a need to understand this phenomenon in more detail. Such work may advance our understanding of one of the most interesting questions in immunology, namely how to eliminate danger in a rapid, efficient and specific manner without causing excess damage to the host.

Published online 11 August 2020
1. Medzhitov, R. Origin and physiological roles of inflammation. Nature 454, 428-435 (2008).

2. van der Poll, T., van de Veerdonk, F. L., Scicluna, B. P. $\&$ Netea, M. G. The immunopathology of sepsis and potential therapeutic targets. Nat. Rev. Immunol. 17 407-420 (2017).

3. Coban, C., Lee, M. S. J. \& Ishii, K. J. Tissue specific immunopathology during malaria infection. Nat. Rev. Immunol. 18, 266-278 (2018).
4. Takeuchi, O. \& Akira, S. Pattern recognition receptors and inflammation. Cell 140, 805-820 (2010). 5. Iwasaki, A. \& Medzhitov, R. Control of adaptive immunity by the innate immune system. Nat. Immunol. 16, 343-353 (2015).

6. Flajnik, M. F. \& Kasahara, M. Origin and evolution of the adaptive immune system: genetic events and selective pressures. Nat. Rev. Genet. 11, 47-59 (2010).

7. Iversen, M. B. et al. An innate antiviral pathway acting before interferons at epithelial surfaces. Nat. Immunol. 17, 150-158 (2016).
8. Yamane, D. et al. Basal expression of interferon regulatory factor 1 drives intrinsic hepatocyte resistance to multiple RNA viruses. Nat. Microbiol. 4 1096-1104 (2019).

9. Thurston, T. L., Ryzhakov, G., Bloor, S., von Muhlinen, N. \& Randow, F. The TBK1 adaptor and autophagy receptor NDP52 restricts the proliferation of ubiquitin-coated bacteria. Nat. Immunol. 10, 1215-1221 (2009).

10. Eddowes, L. A. et al. Antiviral activity of bone morphogenetic proteins and activins. Nat. Microbiol. 4, 339-351 (2019). 
11. Zhang, S. Y. et al. Inborn errors of RNA lariat metabolism in humans with brainstem viral infection. Cell 172, 952-965 (2018). Zhang et al. identify a genetic defect in a novel restriction mechanism that protects against viral brainstem infections

12. Lafaille, F. G. et al. Human SNORA31 variations impair cortical neuron-intrinsic immunity to HSV-1 and underlie herpes simplex encephalitis. Nat. Med. 25, 1873-1884 (2019).

This work identifies SNORA31 as an interferon-independent small antiviral nucleolar RNA conferring protection against herpes simplex encephalitis

13. Nish, S. $\&$ Medzhitov, R. Host defense pathways: role of redundancy and compensation in infectious disease phenotypes. Immunity 34, 629-636 (2011).

14. Ausubel, F. M. Are innate immune signaling pathways in plants and animals conserved? Nat. Immunol. 6, 973-979 (2005).

15. Matzinger, P. Tolerance, danger, and the extended family. Annu. Rev. Immunol. 12, 991-1045 (1994).

16. Liston, A. \& Masters, S. L. Homeostasis-altering molecular processes as mechanisms of inflammasome activation. Nat. Rev. Immunol. 17, 208-214 (2017).

17. Lemaitre, B., Nicolas, E., Michaut, L., Reichhart, J. M. \& Hoffmann, J. A. The dorsoventral regulatory gene cassette spätzle/Toll/cactus controls the potent antifungal response in Drosophila adults. Cell 86 973-983 (1996)

18. Poltorak, A. et al. Defective LPS signaling in $\mathrm{C} 3 \mathrm{H} / \mathrm{HeJ}$ and C57BL/10ScCr mice: mutations in TIr4 gene. Science 282, 2085-2088 (1999).

19. Crow, Y. J. \& Manel, N. Aicardi-Goutieres syndrome and the type I interferonopathies. Nat. Rev. Immunol. 15, 429-440 (2015)

20. Dinarello, C. A., Simon, A. \& van der Meer, J. W. Treating inflammation by blocking interleukin-1 in a broad spectrum of diseases. Nat. Rev. Drug Discov. 11, 633-652 (2012)

21. Rakoff-Nahoum, S., Paglino, J., Eslami-Varzaneh, F., Edberg, S. \& Medzhitov, R. Recognition of commensal microflora by toll-like receptors is required for intestina homeostasis. Cell 118, 229-241 (2004).

22. Barton, E. S. et al. Herpesvirus latency confers symbiotic protection from bacterial infection. Nature 447, 326-329 (2007)

23. Marie, I., Durbin, J. E. \& Levy, D. E. Differential viral induction of distinct interferon-alpha genes by positive feedback through interferon regulatory factor-7. EMBO J. 17, 6660-6669 (1998).

24. Bauernfeind, F. G. et al. Cutting edge: NF-kappaB activating pattern recognition and cytokine receptors license NLRP3 inflammasome activation by regulating NLRP3 expression. J. Immunol. 183, 787-791 (2009).

25. Yan, N., Regalado-Magdos, A. D., Stiggelbout, B. Lee-Kirsch, M. A. \& Lieberman, J. The cytosolic exonuclease TREX1 inhibits the innate immune response to human immunodeficiency virus type 1 . Nat. Immunol. 11, 1005-1013 (2010)

26. Luecke, $\mathrm{S}$. et al. cGAS is activated by DNA in a length-dependent manner. EMBO Rep. 18 1707-1715 (2017)

27. Gehrig, S. et al. Identification of modifications in microbial, native tRNA that suppress immunostimulatory activity. J. Exp. Med. 209, 225-233 (2012)

28. Rice, G. I. et al. Gain-of-function mutations in IFIH1 cause a spectrum of human disease phenotypes associated with upregulated type I interferon signaling. Nat. Genet. 46, 503-509 (2014).

29. Kagan, J. C., Magupalli, V. G. \& Wu, H. SMOCs: supramolecular organizing centres that control innate immunity. Nat. Rev. Immunol. 14, 821-826 (2014).

30. Hamerman, J. A. et al. Negative regulation of TLR signaling in myeloid cells-implications for autoimmun diseases. Immunol. Rev. 269, 212-227 (2016)

31. Carey, C. M. et al. Recurrent loss-of-function mutations reveal costs to OAS1 antiviral activity in primates. Cell Host Microbe 25, 336-343 (2019).

32. Lim, J. K. et al. Genetic variation in OAS 1 is a risk factor for initial infection with West Nile virus in man PLoS Pathog. 5, e1000321 (2009).

33. Li, H. et al. Identification of a Sjogren's syndrome susceptibility locus at OAS1 that influences isoform switching, protein expression, and responsiveness to type I interferons. PLoS Genet. 13, e1006820 (2017).
34. Laguette, N. et al. SAMHD1 is the dendriticand myeloid-cell-specific HIV-1 restriction factor counteracted by Vpx. Nature 474, 654-657 (2011). This work identifies SAMHD1 as an HIV-1 restriction factor that functions through a mechanism dependent on the phosphohydrolase activity of the enzyme.

35. Gariano, G. R. et al. The intracellular DNA sensor IFI 16 gene acts as restriction factor for human cytomegalovirus replication. PLoS Pathog. 8 e1002498 (2012).

36. Orvedahl, A. et al. HSV-1 ICP34.5 confers neurovirulence by targeting the Beclin 1 autophagy protein. Cell Host. Microbe 1, 23-35 (2007).

37. Harris, R. S., Hultquist, J. F. \& Evans, D. T. The restriction factors of human immunodeficiency virus. J. Biol. Chem. 287, 40875-40883 (2012).

38. Duggal, N. K. \& Emerman, M. Evolutionary conflicts between viruses and restriction factors shape immunity. Nat. Rev. Immunol. 12, 687-695 (2012).

39. Bishop, K. N., Holmes, R. K. Sheehy, A. M. $\&$ Malim, M. H. APOBEC-mediated editing of viral RNA Science 305, 645 (2004).

This study describes the identification of APOBEC-mediated RNA editing as a mechanism restricting HIV-1 replication.

40. Neil, S. J., Zang T \& Bieniasz, P. D. Tetherin inhibits retrovirus release and is antagonized by HIV- $1 \mathrm{Vpu}$. Nature 451, 425-430 (2008)

41. Goldstone, D. C. et al. HIV-1 restriction factor SAMHD1 is a deoxynucleoside triphosphate triphosphohydrolase. Nature 480, 379-382 (2011).

42. Glass, M.\& Everett, R. D. Components of promyelocytic leukemia nuclear bodies (ND10) act cooperatively to repress herpesvirus infection. J. Virol. 87, 2174-2185 (2013)

43. Merkl, P. E. \& Knipe, D. M. Role for a filamentous nuclear assembly of IFI 16, DNA, and host factors in restriction of herpesviral infection. mBio 10, e02621 (2019).

44. Pichlmair, A. et al. IFIT1 is an antiviral protein that recognizes 5'-triphosphate RNA. Nat. Immunol. 12 , 624-630 (2011)

45. Full, F. et al. Centrosomal protein TRIM43 restricts herpesvirus infection by regulating nuclear lamina integrity. Nat. Microbiol. 4, 164-176 (2019).

46. Schoggins, J. W. et al. Pan-viral specificity of IFN-induced genes reveals new roles for CGAS in innate immunity. Nature 505, 691-695 (2013).

47. Brien, J. D. et al. Interferon regulatory factor-1 (IRF-1) shapes both innate and $\mathrm{CD} 8^{+} \mathrm{T}$ cell immune responses against West Nile virus infection. PLoS Pathog. 7 e1002230 (2011).

48. Zhou, R. \& Rana, T. M. RNA-based mechanisms regulating host-virus interactions. Immunol. Rev. 253 97-111 (2013).

49. Hamilton, A J \& Baulcombe D. C. A species of small antisense RNA in posttranscriptional gene silencing in plants. Science 286, 950-952 (1999).

50. Mourrain, P. et al. Arabidopsis SGS2 and SGS3 genes are required for posttranscriptional gene silencing and natural virus resistance. Cell 101, 533-542 (2000). Mourrain et al. identify RNAi as an antiviral system in plants.

51. Lu, R. et al. Animal virus replication and RNAi-mediated antiviral silencing in Caenorhabditis elegans. Nature 436, 1040-1043 (2005).

52. Wang, X. H. et al. RNA interference directs innate immunity against viruses in adult Drosophila. Science 312, 452-454 (2006).

53. Galiana-Arnoux, D., Dostert, C., Schneemann, A., Hoffmann, J. A. \& Imler, J. L. Essential function in vivo for Dicer-2 in host defense against RNA viruses in drosophila. Nat. Immunol. 7, 590-597 (2006).

54. Maillard, P. V., van der Veen, A. G., Poirier, E. Z. \& Reis, E. S. C. Slicing and dicing viruses: antiviral RNA interference in mammals. EMBO J. 38, e 100941 (2019).

55. Wang, Y. et al. Hepatitis $C$ virus core protein is a potent inhibitor of RNA silencing-based antiviral response. Gastroenterology 130, 883-892 (2006).

56. Fabozzi, G., Nabel, C. S., Dolan, M. A. \& Sullivan, N. J. Ebolavirus proteins suppress the effects of smal interfering RNA by direct interaction with the mammalian RNA interference pathway. J. Virol. 85 2512-2523 (2011)

57. Yeaman, M. R. \& Yount, N. Y. Mechanisms of antimicrobial peptide action and resistance. Pharmacol. Rev, 55, 27-55 (2003).

58. Wilson, C. L. et al. Regulation of intestinal alphadefensin activation by the metalloproteinase matrilysin in innate host defense. Science 286, 113-117 (1999).
59. Chromek, M. et al. The antimicrobial peptide cathelicidin protects the urinary tract against invasive bacterial infection. Nat. Med. 12, 636-641 (2006)

60. Ganz, T., Metcalf, J. A., Gallin, J. I., Boxer, L. A. \& Lehrer, R. I. Microbicidal/cytotoxic proteins of neutrophils are deficient in two disorders: Chediak-Higashi syndrome and "specific" granule deficiency. J. Clin. Invest. 82, 552-556 (1988).

61. Kumar, P., Kizhakkedathu, J. N. \& Straus, S. K. Antimicrobial peptides: diversity, mechanism of action and strategies to improve the activity and biocompatibility in vivo. Biomolecules 8, 4 (2018).

62. Jenssen, H., Hamill, P. \& Hancock, R. E. Peptide antimicrobial agents. Clin. Microbiol. Rev. 19, 491-511 (2006).

63. Valore, E. V. et al. Human beta-defensin-1: an antimicrobial peptide of urogenital tissues. J. Clin. Invest. 101, 1633-1642 (1998).

64. Nizet, V. et al. Innate antimicrobial peptide protects the skin from invasive bacterial infection. Nature $\mathbf{4 1 4}$ 454-457 (2001)

65. Ouinones-Mateu, M. E et al. Human epithelial beta-defensins 2 and 3 inhibit HIV- 1 replication. AIDS 17, F39-F48 (2003).

66. Ahmed, A., Siman-Tov, G., Hall, G., Bhalla, N. \& Narayanan, A. Human antimicrobial peptides as therapeutics for viral infections. Viruses 11, 704 (2019).

67. Casals, C., Garcia-Fojeda, B. \& Minutti, C. M Soluble defense collagens: sweeping up immune threats. Mol. Immunol. 112, 291-304 (2019).

68. Meschi, J. et al. Surfactant protein D binds to human immunodeficiency virus (HIV) envelope protein gp120 and inhibits HIV replication. J. Gen. Virol. 86, 3097-3107 (2005).

69. Hartshorn, K. L. et al. Reduced influenza viral neutralizing activity of natural human trimers of surfactant protein D. Respir. Res. 8, 9 (2007).

70. Reading, P. C. et al. Antiviral activity of the long chain pentraxin PTX3 against influenza viruses. J. Immunol. $180,3391-3398$ (2008)

71. LeVine, A. M., Whitsett, J. A., Hartshorn, K. L., Crouch, E. C. \& Korfhagen, T. R. Surfactant protein D enhances clearance of influenza $A$ virus from the lung in vivo. J. Immunol. 167, 5868-5873 (2001).

72. Jounblat, R. et al. Binding and agglutination of Streptococcus pneumoniae by human surfactant protein D (SP-D) vary between strains, but SP-D fails to enhance killing by neutrophils. Infect. Immun. 72, 709-716 (2004)

73. Isaacs, C. E. \& Xu, W. Theaflavin-3,3'-digallate and lactic acid combinations reduce herpes simplex virus infectivity. Antimicrob. Agents. Chemother. 57 3806-3814 (2013).

74. Tyssen, D. et al. Anti-HIV-1 activity of lactic acid in human cervicovaginal fluid. mSphere 3, e00055 (2018).

75. Sanchez, E. L. \& Lagunoff, M. Viral activation of cellular metabolism. Virology 479-480, 609-618 (2015).

76. Munger, J., Bajad, S. U., Coller, H. A., Shenk, T. \& Rabinowitz, J. D. Dynamics of the cellular metabolome during human cytomegalovirus infection. PLoS Pathog. 2, e132 (2006)

77. Libran-Perez, M., Pereiro, P., Figueras, A. \& Novoa, B. Antiviral activity of palmitic acid via autophagic flux inhibition in zebrafish (Danio rerio). Fish Shellfish Immunol. 95, 595-605 (2019).

78. Kachroo, A. et al. An oleic acid-mediated pathway induces constitutive defense signaling and enhanced resistance to multiple pathogens in soybean. Mol. Plant Microbe Interact 21, 564-575 (2008).

79. Nevo, Y. \& Nelson, N. The NRAMP family of metal-ion transporters. Biochim. Biophys. Acta 1763, 609-620 (2006).

80. Vidal, S. M., Malo, D., Vogan, K., Skamene, E. \& Gros, P. Natural resistance to infection with intracellular parasites: isolation of a candidate for Bcg. Cell 73, 469-485 (1993).

81. Plant, J. E., Blackwell, J. M., O'Brien, A. D., Bradley, D. J. \& Glynn, A. A. Are the Lsh and Ity disease resistance genes at one locus on mouse chromosome 1? Nature 297, 510-511 (1982).

82. Supek, F., Supekova, L., Nelson, H. \& Nelson, N. A yeast manganese transporter related to the macrophage protein involved in conferring resistance to mycobacteria. Proc. Natl Acad. Sci. USA 93 5105-5110 (1996).

83. Mayeur, S., Spahis, S., Pouliot, Y. \& Levy, E. Lactoferrin, a pleiotropic protein in health and disease. Antioxid. Redox Signal. 24, 813-836 (2016). 
84. Velusamy, S. K., Markowitz, K., Fine, D. H. \& Velliyagounder, K. Human lactoferrin protects against Streptococcus mutans-induced caries in mice. Oral Dis. 22, 148-154 (2016)

85. Levine, B., Mizushima, N. \& Virgin, H. W. Autophagy in immunity and inflammation. Nature 469, 323-335 (2011).

86. Lim, J. J., Grinstein, S. \& Roth, Z. Diversity and versatility of phagocytosis: roles in innate immunity, tissue remodeling, and homeostasis. Front. Cell. Infect Microbiol. 7, 191 (2017).

87. Thurston, T. L. M., Wandel, M. P., von Muhlinen, N., Foeglein, A. \& Randow, F. Galectin 8 targets damaged vesicles for autophagy to defend cells against bacteria invasion. Nature 482, 414-418 (2012).

88. Gros, P., Milder, F. J. \& Janssen, B. J. Complement driven by conformational changes. Nat. Rev. Immunol. 8, 48-58 (2008).

89. Orvedahl, A. et al. Autophagy protects against Sindbis virus infection of the central nervous system. Cell Host Microbe 7, 115-127 (2010).

This study identifies an essential role for autophagy in antiviral defence in vitro and in vivo in mice.

90. Sparrer, K. M. J. et al. TRIM23 mediates virus-induced autophagy via activation of TBK1. Nat. Microbiol. 2 , 1543-1557 (2017)

91. Franco, L. H. et al. The ubiquitin ligase Smurf1 functions in selective autophagy of Mycobacterium tuberculosis and anti-tuberculous host defense. Cell Host Microbe 21, 59-72 (2017).

92. Huett, A. et al. The LRR and RING domain protein LRSAM 1 is an E3 ligase crucial for ubiquitin-dependent autophagy of intracellular Salmonella Typhimurium. Cell Host Microbe 12, 778-790 (2012).

93. Wild, P. et al. Phosphorylation of the autophagy receptor optineurin restricts Salmonella growth. Science 333, 228-233 (2011)

94. Ravenhill, B. J. et al. The cargo receptor NDP52 initiates selective autophagy by recruiting the ULK complex to cytosol-invading bacteria. Mol. Cell 74, 320-329 (2019).

95. Gutierrez, M. G et al. Autophagy is a defense mechanism inhibiting BCG and Mycobacterium tuberculosis survival in infected macrophages. Cell 119, 753-766 (2004)

This work provides the first description of autophagy as an antibacterial mechanism.

96. Castillo, E. F. et al. Autophagy protects against active tuberculosis by suppressing bacterial burden and inflammation. Proc. Natl Acad. Sci. USA 109 E3168-E3176 (2012)

97. Kimmey, J. M. et al. Unique role for ATC5 in neutrophilmediated immunopathology during $M$. tuberculosis infection. Nature 528, 565-569 (2015).

98. Ricklin, D., Reis, E. S. \& Lambris, J. D. Complement in disease: a defence system turning offensive. Nat. Rev. Nephrol. 12, 383-401 (2016).

99. Shi, L. et al. Mannose-binding lectin-deficient mice are susceptible to infection with Staphylococcus aureus. J. Exp. Med. 199, 1379-1390 (2004).

100. Whitnack, E. \& Beachey, E. H. Inhibition of complement-mediated opsonization and phagocytosis of Streptococcus pyogenes by $D$ fragments of fibrinogen and fibrin bound to cell surface M protein. J. Exp. Med. 162, 1983-1997 (1985).

101. Heckmann, B. L., Boada-Romero, E., Cunha, L. D., Magne, J. \& Green, D. R. LC3-associated phagocytosis and inflammation. J. Mol. Biol. 429, 3561-3576 (2017)

102. Martinez, J. et al. Noncanonical autophagy inhibits the autoinflammatory, lupus-like response to dying cells. Nature 533, 115-119 (2016)

103. Martinez, J. et al. Molecular characterization of LC3-associated phagocytosis reveals distinct roles for Rubicon, NOX2 and autophagy proteins. Nat. Cell. Biol. 17, 893-906 (2015).

104. Wang, Y. \& Le, W. D. Autophagy and ubiquitinproteasome system. Adv. Exp. Med. Biol. 1206 527-550 (2019).

105. Hauler, F., Mallery, D. L., McEwan, W. A., Bidgood, S. R. $\S$ James, L. C. AAA ATPase p97/VCP is essential for TRIM21-mediated virus neutralization. Proc. Natl Acad. Sci. USA 109, 19733-19738 (2012). These authors identify an important role for the ubiquitin-proteasome pathway in cytosolic neutralization of viral capsids.

106. Tam, J. C., Bidgood, S. R., McEwan, W. A. \& James, L. C. Intracellular sensing of complement $\mathrm{C} 3$ activates cell autonomous immunity. Science 345, 1256070 (2014).

107. Bottermann, M. et al. Complement C4 prevents viral infection through capsid inactivation. Cell Host Microbe 25, 617-629 e617 (2019).
108. Camborde, L. et al. The ubiquitin-proteasome system regulates the accumulation of Turnip yellow mosaic virus RNA-dependent RNA polymerase during viral infection. Plant Cell 22, 3142-3152 (2010).

109. Ruckdeschel, K. et al. The proteasome pathway destabilizes Yersinia outer protein $\mathrm{E}$ and represses its antihost cell activities. J. Immunol. 176, 6093-6102 (2006).

110. Sahana, N. et al. Inhibition of the host proteasome facilitates papaya ringspot virus accumulation and proteosomal catalytic activity is modulated by viral factor HcPro. PLoS ONE 7, e52546 (2012).

111. Xu, Y. et al. Rice stripe tenuivirus nonstructural protein 3 hijacks the $26 \mathrm{~S}$ proteasome of the small brown planthopper via direct interaction with regulatory particle non-ATPase subunit 3 . J. Virol. 89, 4296-4310 (2015)

112. Dudnik, A., Bigler, L. \& Dudler, R. Production of proteasome inhibitor syringolin $A$ by the endophyte Rhizobium sp. strain AP16. Appl. Environ. Microbiol. 80, 3741-3748 (2014).

113. Groll, M. et al. A plant pathogen virulence factor inhibits the eukaryotic proteasome by a nove mechanism. Nature 452, 755-758 (2008).

114. Zimmermann, C. et al. The abundant tegument protein pUL25 of human cytomegalovirus prevents proteasomal degradation of pUL26 and supports its suppression of ISGylation. J. Virol. 92, e01180-e01218 (2018).

115. Chakrabarti, A., Jha, B. K. \& Silverman, R. H. New insights into the role of RNase $\mathrm{L}$ in innate immunity. J. Interferon Cytokine Res. 31, 49-57 (2011).

116. Banerjee, S. et al. OAS-RNase L innate immune pathway mediates the cytotoxicity of a DNA-demethylating drug Proc. Natl Acad. Sci. USA 116, 5071-5076 (2019).

117. Birdwell, L. D. et al. Activation of RNase $L$ by murine coronavirus in myeloid cells is dependent on basal Oas gene expression and independent of virus-induced interferon. J. Virol. 90, 3160-3172 (2016).

118. Stetson, D. B., Ko, J. S., Heidmann, T. \& Medzhitov, R. Trex 1 prevents cell-intrinsic initiation of autoimmunity. Cell 134, 587-598 (2008).

119. Mogensen, T. H. Pathogen recognition and inflammatory signaling in innate immune defenses. Clin. Microbiol. Rev. 22, 240-273 (2009).

120. Stavrou, S., Blouch, K., Kotla, S., Bass, A. \& Ross, S. R. Nucleic acid recognition orchestrates the anti-viral response to retroviruses. Cell Host Microbe 17 478-488 (2015)

Stavrou et al. show that lack of the restriction factor APOBEC3 leads to higher load of retroviral nucleic acids, and increased STING-dependent IFN $\beta$ expression.

121. Maelfait, J., Bridgeman, A., Benlahrech, A., Cursi, C. \& Rehwinkel, J. Restriction by SAMHD1 limits cGAS/ STING-dependent innate and adaptive immune responses to HIV-1. Cell Rep. 16, 1492-1501 (2016).

This work shows that SAMHD1 limits lentivirusinduced type I interferon production and $\mathrm{T}$ cell cytotoxicity, thus providing direct evidence for constitutive immune responses limiting inducible immune activities

122. Marques, J. T. et al. A structural basis for discriminating between self and nonself double-stranded RNAs in mammalian cells. Nat. Biotechnol. 24, 559-565 (2006).

123. Britigan, B. E., Lewis, T. S., Waldschmidt, M. McCormick, M. L. \& Krieg, A. M. Lactoferrin binds CpG-containing oligonucleotides and inhibits their immunostimulatory effects on human B cells. J. Immunol. 167, 2921-2928 (2001).

124. Cheng, J. et al. Autophagy regulates MAVS signaling activation in a phosphorylation-dependent manner in microglia. Cell Death Differ. 24, 276-287 (2017).

125. Tal, M. C. et al. Absence of autophagy results in reactive oxygen species-dependent amplification of RLR signaling. Proc. Natl Acad. Sci. USA 106, 2770-2775 (2009).

126. Prabakaran, T. et al. Attenuation of cGAS-STING signaling is mediated by a p62/SOSTM1-dependent autophagy pathway activated by TBK 1 . EMBO J. 37, e97858 (2018).

Cheng et al. (2017), Tal et al. (2009) and Prabakaran et al. show that autophagy directly inhibits signalling by the RIG-I-like receptor-MAVS and CGAS-STING pathways

127. Aden, K. et al. ATG $16 \mathrm{~L} 1$ orchestrates interleukin-22 signaling in the intestinal epithelium via cCAS-STING. J. Exp. Med. 215, 2868-2886 (2018).
128. Zhang, W. et al. Lactate is a natural suppressor of RLR signaling by targeting MAVS. Cell 178, 176-189.e15 (2019).

This report shows that lactate directly inhibits RIG-I-like receptor-MAVS signalling.

129. Shim, D. W. et al. Anti-inflammatory action of an antimicrobial model peptide that suppresses the TRIF-dependent signaling pathway via inhibition of toll-like receptor 4 endocytosis in lipopolysaccharidestimulated macrophages. PLOS ONE 10, e0126871 (2015).

130. Haber, J. E. Deciphering the DNA damage response. Cell 162, 1183-1185 (2015).

131. Johnston, J. A., Ward, C. L. \& Kopito, R. R. Aggresomes: a cellular response to misfolded proteins. J. Cell. Biol. 143, 1883-1898 (1998)

132. Fortun, J., Dunn, W. A. Jr, Joy, S., Li, J. \& Notterpek, L. Emerging role for autophagy in the removal of aggresomes in Schwann cells. J. Neurosci. 23, 10672-10680 (2003).

133. Holze, C. et al. Oxeiptosis, a ROS-induced caspaseindependent apoptosis-like cell-death pathway. Nat. Immunol. 19, 130-140 (2018).

134. Yu, X. H., Zhang, D. W., Zheng, X. L. \& Tang, C. K Cholesterol transport system: an integrated cholesterol transport model involved in atherosclerosis. Prog. Lipid Res. 73, 65-91 (2019).

135. Mackenzie, K. J. et al. cGAS surveillance of micronuclei links genome instability to innate immunity. Nature 548, 461-465 (2017).

136. Harding, S. M. et al. Mitotic progression following DNA damage enables pattern recognition within micronuclei. Nature 548, 466-470 (2017).

137. Crow, Y. J. et al. Mutations in the gene encoding the 3'-5' DNA exonuclease TREX1 cause Aicardi-Goutieres syndrome at the AGS1 locus. Nat. Genet. 38 917-920 (2006)

Loss-of-function mutations in the gene encoding the DNA exonuclease TREX1 lead to constitutive type I interferon signalling.

138. Rodero, M. P. et al. Type I interferon-mediated autoinflammation due to DNase II deficiency. Nat. Commun. 8, 2176 (2017).

139. Halle, A. et al. The NALP3 inflammasome is involved in the innate immune response to amyloid-beta. Nat. Immunol. 9, 857-865 (2008).

140. Duewell, P. et al. NLRP3 inflammasomes are required for atherogenesis and activated by cholesterol crystals. Nature 464, 1357-1361 (2010)

141. Laplana, M., Caruz, A., Pineda, J. A., Puig, T. \& Fibla, J. Association of BST-2 gene variants with HIV disease progression underscores the role of BST-2 in HIV type 1 infection. J. Infect. Dis. 207, 411-419 (2013).

142. Everitt, A. R. et al. IFITM3 restricts the morbidity and mortality associated with influenza. Nature $\mathbf{4 8 4}$ 519-523 (2012)

143. Tesse, R. et al. Association of beta-defensin- 1 gene polymorphisms with Pseudomonas aeruginosa airway colonization in cystic fibrosis. Genes Immun. 9, 57-60 (2008).

144. Shao, Y. et al. Association between genetic polymorphisms in the autophagy-related 5 gene promoter and the risk of sepsis. Sci. Rep. 7, 9399 (2017)

145. Yordy, B., lijima, N., Huttner, A., Leib, D. \& Iwasaki, A. A neuron-specific role for autophagy in antiviral defense against herpes simplex virus. Cell Host Microbe 12, 334-345 (2012).

146. Wu, X. et al. Intrinsic immunity shapes viral resistance of stem cells. Cell 172, 423-438 e425 (2018).

147. Eggenberger, J., Blanco-Melo, D., Panis, M., Brennand, K. J. \& Tenoever, B. R. Type I interferon response impairs differentiation potential of pluripotent stem cells. Proc. Natl Acad. Sci. USA 116 1384-1393 (2019).

148. Liu, Y. et al. Mutations in proteasome subunit beta type 8 cause chronic atypical neutrophilic dermatosis with lipodystrophy and elevated temperature with evidence of genetic and phenotypic heterogeneity. Arthritis Rheum. 64, 895-907 (2012).

149. Brehm, A. et al. Additive loss-of-function proteasome subunit mutations in CANDLE/PRAAS patients promote type I IFN production. J. Clin. Invest. 125 4196-4211 (2015)

These authors report that patients with mutations in genes encoding proteasome subunits develop disease with a type I interferon signature.

150. Massaad, M. J. et al. Deficiency of base excision repair enzyme NEIL3 drives increased predisposition to autoimmunity. J. Clin. Invest. 126, 4219-4236 (2016). 
151. Khor, T. O. et al. Nrf2-deficient mice have an increased susceptibility to dextran sulfate sodium-induced colitis. Cancer Res. 66, 11580-11584 (2006).

152. Ivanciuc, T., Sbrana, E., Casola, A. \& Garofalo, R. P. Protective role of nuclear factor erythroid 2-related factor 2 against respiratory syncytial virus and human metapneumovirus infections. Front. Immunol. 9, 854 (2018).

153. Peyssonnaux, C. et al. HIF-1 alpha expression regulates the bactericidal capacity of phagocytes. J. Clin. Invest. 115, 1806-1815 (2005).

154. Blondeau, C. et al. Tetherin restricts herpes simplex virus 1 and is antagonized by glycoprotein $\mathrm{M}$. J. Virol. 87, 13124-13133 (2013).

155. Smith, S. E. et al. Interferon-induced transmembrane protein 1 restricts replication of viruses that enter cells via the plasma membrane. J. Virol. 93, e02003 (2019).

156. Bernhardt, A. et al. Inflammatory cell infiltration and resolution of kidney inflammation is orchestrated by the cold-shock protein Y-box binding protein-1. Kidney Int 92, 1157-1177 (2017).

157. Hollenbaugh, J. A. et al. Host factor SAMHD restricts DNA viruses in non-dividing myeloid cells. PLoS Pathog. 9, e1003481 (2013).

158. Nakaya, Y., Stavrou, S., Blouch, K., Tattersall, P. \& Ross, S. R. In vivo examination of mouse APOBEC3and human APOBEC3A- and APOBEC3G-mediated restriction of parvovirus and herpesvirus infection in mouse models. J. Virol. 90, 8005-8012 (2016).

159. Girardi, E. et al. Cross-species comparative analysis of Dicer proteins during Sindbis virus infection. Sci. Rep. 5, 10693 (2015)

160. Dombrowski, Y. et al. Cytosolic DNA triggers inflammasome activation in keratinocytes in psoriatic lesions. Sci. Transl. Med. 3, 82 ra38 (2011).

161. Stamme, C., Muller, M., Hamann, L., Gutsmann, T. \& Seydel, U. Surfactant protein a inhibits lipopolysaccharide-induced immune cell activation by preventing the interaction of lipopolysaccharide with lipopolysaccharide-binding protein. Am. J. Respir Cell Mol. Biol. 27, 353-360 (2002).

162. Daniels, B. P. et al. The nucleotide sensor ZBP1 and kinase RIPK3 induce the enzyme IRG1 to promote an antiviral metabolic state in neurons. Immunity $\mathbf{5 0}$, 64-76 e64 (2019).

163. Nair, S. et al. Irg 1 expression in myeloid cells prevents immunopathology during $M$. tuberculosis infection. J. Exp. Med. 215, 1035-1045 (2018).
164. Jessop, F., Hamilton, R. F., Rhoderick, J. F., Shaw, P. K. $\&$ Holian, A. Autophagy deficiency in macrophages enhances NLRP3 inflammasome activity and chronic lung disease following silica exposure. Toxicol. Appl. Pharmacol. 309, 101-110 (2016).

165. Meissner, F. et al. Inflammasome activation in NADPH oxidase defective mononuclear phagocytes from patients with chronic granulomatous disease. Blood 116, 1570-1573 (2010)

166. Segal, B. H. et al. NADPH oxidase limits innate immune responses in the lungs in mice. PLOS ONE 5, e9631 (2010).

167. Gluschko, A. et al. The beta2 integrin Mac-1 induces protective LC3-associated phagocytosis of listeria monocytogenes. Cell Host Microbe 23, 324-337 e325 (2018).

168. Gong, L. et al. The Burkholderia pseudomallei type III secretion system and BopA are required for evasion of LC3-associated phagocytosis. PLOS ONE 6, e 17852 (2011).

169. Masters, S. L., Simon, A., Aksentijevich, I. \& Kastner, D. L. Horror autoinflammaticus: the molecular pathophysiology of autoinflammatory disease. Ann. Rev. Immunol. 27, 621-668 (2009).

170. Uggenti, C., Lepelley, A. \& Crow, Y. J. Self-awareness: nucleic acid-driven inflammation and the type interferonopathies. Annu. Rev. Immunol. 37. 247-267 (2019)

171. Jesus, A. A. \& Goldbach-Mansky, R. IL-1 blockade in autoinflammatory syndromes. Annu. Rev. Med. 65 223-244 (2014)

172. Schwartz, D. M. et al. JAK inhibition as a therapeutic strategy for immune and inflammatory diseases. Nat. Rev. Drug. Discov. 17, 78 (2017).

173. Kim, H., Sanchez, G. A. \& Goldbach-Mansky, R. Insights from Mendelian interferonopathies: comparison of CANDLE, SAVI with AGS, monogenic lupus. J. Mol. Med. 94, 1111-1127 (2016).

174. Sanjuan, M. A. et al. Toll-like receptor signalling in macrophages links the autophagy pathway to phagocytosis. Nature 450, 1253-1257 (2007).

175. Doyle, S. E. et al. Toll-like receptors induce a phagocytic gene program through p38. J. Exp. Med. 199, 81-90 (2004).

176. Henneke, P. et al. Cellular activation, phagocytosis, and bactericidal activity against group B streptococcus involve parallel myeloid differentiation factor 88-dependent and independent signaling pathways J. Immunol. 169, 3970-3977 (2002).
177. Hawley, K. L. et al. CD14 cooperates with complement receptor 3 to mediate MyD88-independent phagocytosis of Borrelia burgdorferi. Proc. Natl Acad. Sci. USA 109, 1228-1232 (2012).

178. Peng, G., Lei, K. J., Jin, W., Greenwell-Wild, T. \& Wahl, S. M. Induction of APOBEC3 family proteins, a defensive maneuver underlying interferon-induced anti-HIV-1 activity. J. Exp. Med. 203, 41-46 (2006).

179. Walmsley, S. R. et al. Prolyl hydroxylase 3 (PHD3) is essential for hypoxic regulation of neutrophilic inflammation in humans and mice. J. Clin. Invest. 121 1053-1063 (2011).

180. Olagnier, D. et al. Nrf2 negatively regulates STING indicating a link between antiviral sensing and metabolic reprogramming. Nat. Commun. 9, 3506 (2018).

\section{Acknowledgements}

S.R.P. is funded by the European Research Council (ERC-AdG ENVISION; 786602), the Novo Nordisk Foundation (NNF18OC0030274) and the Lundbeck Foundation (R1982015-171 and R268-2016-3927). T.P. is funded by the European Research Council (ERC-StG IDEM. 637647). S.L.M. acknowledges funding from a Howard Hughes Medical Institute-Wellcome International Research Scholarship and the Sylvia and Charles Viertel Foundation. T.H.M. received funding from Aarhus University Research Foundation (AUFF-E-215-FLS-8-66), the Danish Council for Independent Research-Medical Sciences (4004-00047B) and the Lundbeck Foundation (R268-2016-3927). The authors thank D. Olagnier for critical reading of the manuscript and comments and suggestions.

Author contributions

S.R.P. conceived the idea and wrote the first version of the manuscript together with T.H.M. All authors together fully developed the work, and drafted, finalized and revised the manuscript.

Competing interests

The authors declare no competing interests.

Peer review information

Nature Reviews Immunology thanks the anonymous reviewer(s) for their contribution to the peer review of this work.

Publisher's note

Springer Nature remains neutral with regard to jurisdictional claims in published maps and institutional affiliations.

C) Springer Nature Limited 2020 